Portland State University

PDXScholar

Fall 11-14-2017

\title{
Examining the Structure of the Modus Operandi Questionnaire for Adult \& Juvenile Sex Offenders
}

Judith Gayle Zatkin

Portland State University

Follow this and additional works at: https://pdxscholar.library.pdx.edu/open_access_etds

Part of the Psychology Commons

Let us know how access to this document benefits you.

\section{Recommended Citation}

Zatkin, Judith Gayle, "Examining the Structure of the Modus Operandi Questionnaire for Adult \& Juvenile Sex Offenders" (2017). Dissertations and Theses. Paper 4073.

https://doi.org/10.15760/etd.5957

This Thesis is brought to you for free and open access. It has been accepted for inclusion in Dissertations and Theses by an authorized administrator of PDXScholar. Please contact us if we can make this document more accessible: pdxscholar@pdx.edu. 
Examining the Structure of the Modus Operandi Questionnaire for

Adult \& Juvenile Sex Offenders

by

Judith Gayle Zatkin

A thesis submitted in partial fulfillment of the requirements for the degree of

Master of Science

in

Psychology

Thesis Committee:

Keith Kaufman, Chair

Joel Steele

Greg Townley

Portland State University

2017 


\begin{abstract}
Child sexual abuse is a pervasive crime that has numerous negative short and longterm impacts on its victims, as well as negative impacts for society. Modus Operandi (MO) is defined as a pattern of perpetration utilized by those who commit CSA to successfully abuse a child without detection. Understanding how CSA is perpetrated through MO is essential, as this construct influences both prevention of CSA, and treatment for victims and perpetrators. The Modus Operandi Questionnaire (Kaufman, 1991; MOQ) is the first and most comprehensive measurement tool for CSA MO, and is utilized by both researchers and clinicians. This study provides an up-to-date factor analysis of the MOQ, breaking the measure into five stage-based scales (i.e.; Accessing the victim, Gaining the victim's trust, Gaining the victim's cooperation, Sexual Abuse, and Silencing after the abuse). Each stage-based scale was analyzed through Exploratory Factor Analysis to determine structure followed by a Confirmatory Factor Analysis to examine model fit, as well as loadings of first-order factors onto their respective stage-based second order factors. Although model fit for all five scales can be improved, the results of this study determined reliable factors within all five scales, and show a structure that can be utilized to further inform research, treatment, and prevention of CSA.
\end{abstract}




\section{Acknowledgments}

I would like to thank my wonderful committee for their support through this process. Thank you to my advisor, Dr. Keith Kaufman, for his unending moral support and project guidance, to Dr. Joel Steele, for the copious amount of statistical consultation he provided, and to Dr. Greg Townley, for quick and encouraging responses to all aspects of the thesis process. The guidance and suggestions this committee gave throughout the development of this project have been necessary for its success. I would also like to thank Dr. Todd Bodner for additional statistical consultation. Finally, I would like to thank my family, my partner, and my friends for providing a social support system that has been an essential part of my thesis process. 


\section{Table of Contents}

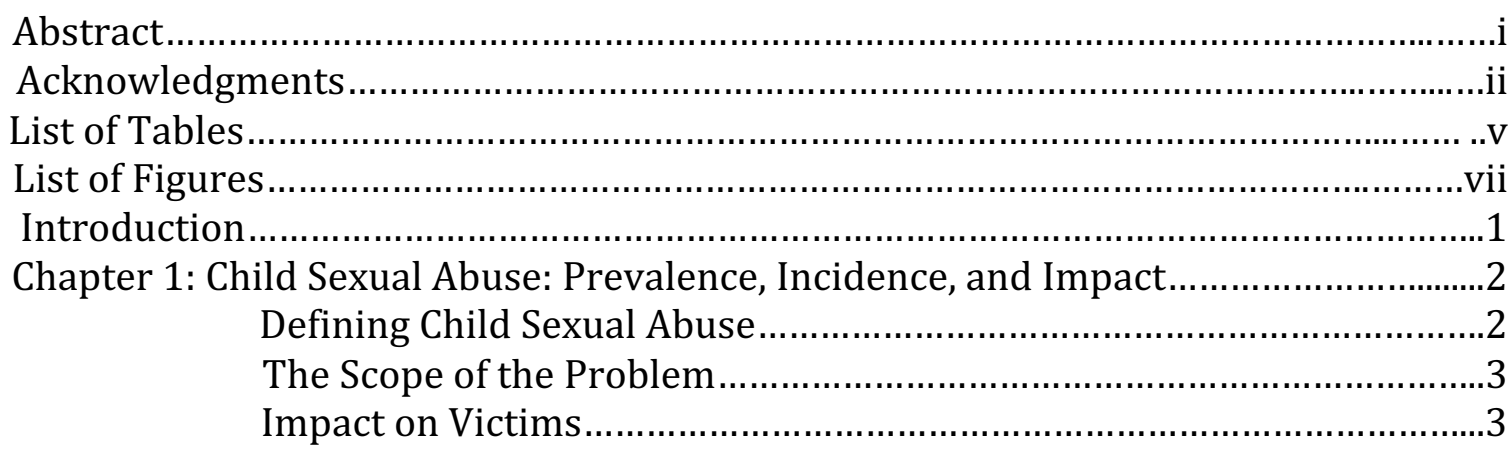

Chapter 2: Rational Choice Theory and Crime Perpetration........................................

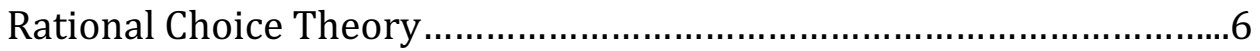

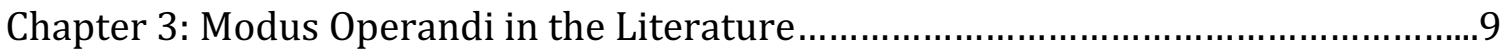

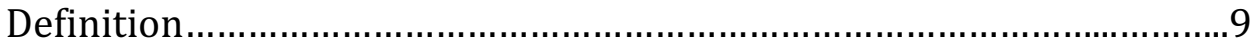

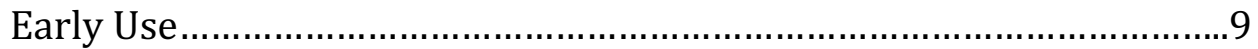

The Modus Operandi Questionnaire.................................................10

Situational Factors......................................................................1

Offender Age ................................................................................12

Victim Age and Gender ................................................................12

Offender-Victim Relationship.........................................................13

MO Research Since 2009................................................................14

Chapter 4: The MOQ: Description and Psychometric Development...........................16

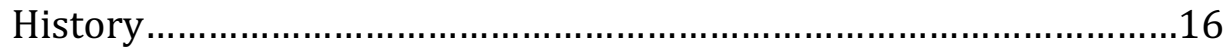

Description..........................................................................

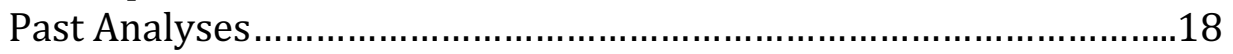

Change Over Time.....................................................................21

Chapter 5: Modus Operandi and Prevention.........................................................22

The Public Health Model of Prevention.............................................22

MO and Clinical Treatment..........................................................24

MO and Prevention..................................................................2

Chapter 6: Literature Critique and Justification for the Current Study.......................29

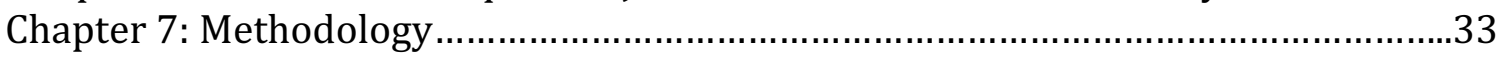

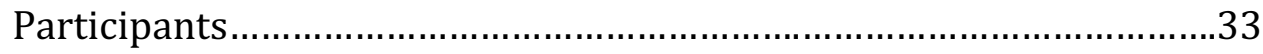

Design

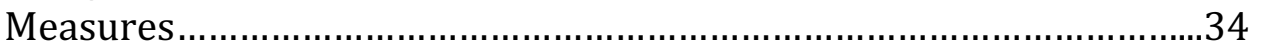

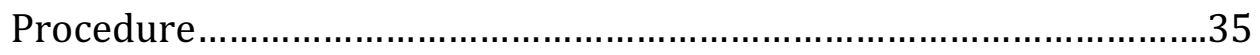

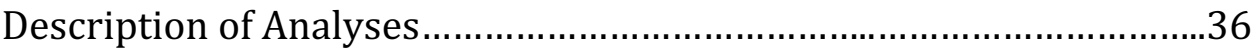

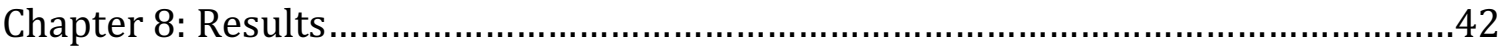

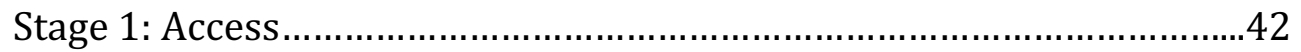

Stage 2: Gaining Trust........................................................................4

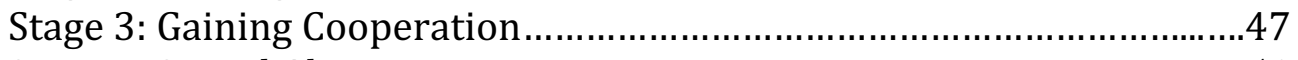

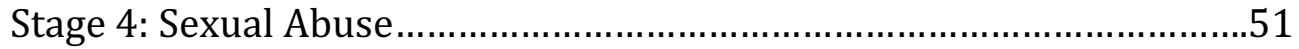




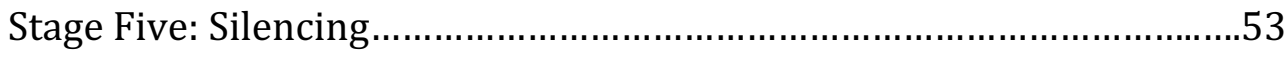

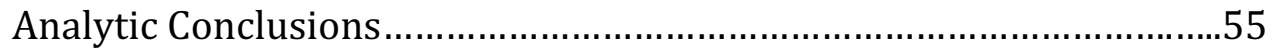

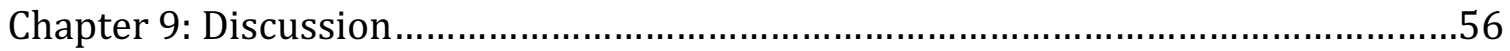

Strengthening the MOQ as a Research Measure..................................57

Group Differences and the MOQ as a Research Measure......................63

Other Variables to Augment the MOQ ................................................65

Future MOQ Confirmatory Factor Analyses.......................................66

Future Directions as a Research Tool ...............................................66

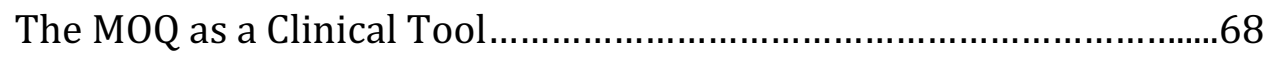

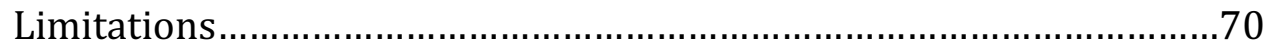

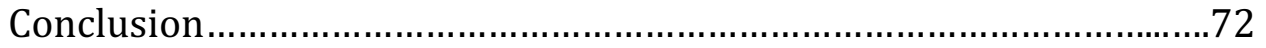

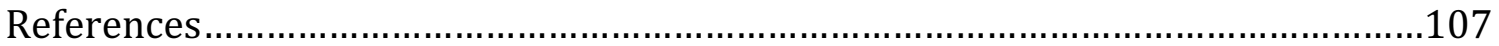




\section{List of Tables}

Table 1

Low Endorsement MOQ Items

Table 2

Access Factor Correlations

Table 3

Trust Factor Correlations

Table 4

Cooperation Factor Correlations

Table 5

Sexual Abuse Factor Correlations

Table 6

Access Exploratory Factor Loadings

Table 7

Access Model Path Estimates

Table 8

Gaining Trust Exploratory Factor Loadings

Table 9

Gaining Trust Model Path Estimates

Table 10

Gaining Cooperation Exploratory Factor Loadings 
Gaining Cooperation Model Path Estimates

Table 12

Sexual Abuse Exploratory Factor Loadings

Table 13

Sexual Abuse Model Path Estimates

Table 14

Silencing Exploratory Factor Loadings

Table 15

Silencing Model Path Estimates 


\section{List of Figures}

Figure 1

Accessing Scree Plot

Figure 2

Access Model

Figure 3

Gaining Trust Scree Plot

Figure 4

Gaining Trust Model

Figure 5

Cooperation Scree Plot

Figure 6

Gaining Cooperation Model

Figure 7

Sexual Abuse Scree Plot

Figure 8

Sexual Abuse Model

Figure 9

Silencing Scree Plot

Figure 10

Silencing Model 


\section{Introduction}

Child sexual abuse (CSA) is a pervasive public health issue, negatively impacting the lives of victims and their loved ones every day. Due to the numerous negative effects of CSA, it is imperative that the way in which those who perpetrate this serious crime operate is studied to best cultivate prevention efforts. Modus operandi, or the way in which perpetrators commit their crimes, is a useful tool for understanding how CSA perpetrators operate. Modus operandi is a common concept in criminological research, and has been measured in a variety of ways, including using archival data, interview based data, and self-report surveys. The Modus Operandi Questionnaire (MOQ; Kaufman, 1994) is the only self-report measure that accounts for the full scope of CSA offenders' modus operandi. This study demonstrates that CSA is both pervasive and problematic. It also gives insight into how modus operandi has been used to study sexual offending, as well as past psychometrics of the MOQ. To better measure modus operandi, this study shows the results of a factor analysis, using Structural Equation Modeling (SEM) to fit the results of an Exploratory Factor Analysis, demonstrating reliability and validity of the MOQ. This study has the potential to lead to positive advancements for sex offender research, clinical work, and prevention. 


\section{Chapter I:}

\section{Child Sexual Abuse: Prevalence, Incidence, and Impact}

Prior to discussing the way in which child sexual abuse is perpetrated, and how it can be prevented, it is important to develop an understanding of what CSA is, as well as how often it occurs. While experts agree that the problem is both pervasive and severe, there are differing definitions of the phenomenon. The following chapter defines CSA, and discusses the scope of the problem as well as its impact on both victims and society at large.

\section{Defining Child Sexual Abuse}

CSA definitions vary based on a number of factors. Definitional discrepancies exist between victims and perpetrators, as well as within categories based on age, and dependent upon the type of contact that constitutes abuse (Wyatt \& Peters, 1986). The broadest definition, used by the Center for Disease Control (2007), states that CSA is sexual activity with an underage minor that cannot consent to the activity. The World Health Organization (Butchart, Harvey, Mian, \& Furniss, 2006) expands upon this definition, suggesting that sexual abuse is any activity for which the victim is not developmentally prepared. They also state that both children and adults can commit CSA, but that perpetrators will have a position of power over or be trusted by their victim. For the purpose of this study, both juvenile and adult offenders will be considered (with juvenile offenders being under the age of 18 at the time of their offense). At the same time, victims will be under the age of 18, and 
both contact (abuse that involves touching the victim) and non-contact (no touch involved) abuse will be considered.

\section{The Scope of the Problem}

Due to the broad array of definitions used to measure incidence and prevalence of CSA, as well as a lack of reporting, it is difficult to pinpoint the exact scope of the problem. However, even with these issues, it is known that CSA is far too common an occurrence. A meta-analysis examining 100 international studies to better understand the epidemiology of CSA indicated that worldwide, 7.9\% of men and $19.7 \%$ of women are sexually abused in some way before they turn 18 years of age (Pereda, Guilera, Forns, \& Gómez-Benito, 2009). In the United States alone, prevalence rates are $7.5 \%$ for men and $25.3 \%$ for women (Pereda, Guilera, Forns, \& Gómez-Benito, 2009). Further, many instances of CSA are never reported. Baker, Connaughton \& Zhang (2010) indicate that only between $10 \%$ and $35 \%$ of CSA incidents are ever reported, which means that current incidence rates are likely too low. Overall, child sexual abuse is a pervasive societal problem that impacts many people.

\section{Impact on Victims}

Child sexual abuse is a particularly troublesome public health issue due to the severe short- and long-term impacts that it has on its victims. Though consequences manifest differently based on the individual victim, most victims do experience some degree of negative consequences. 
Short- term consequences of CSA victimization can be both physical and psychological in nature. The victim may be physically injured due to a more aggressive attack, making injuries common (Wolfe, Jaffe, Jette, \& Poisson, 2003). Psychologically, feelings of low self-esteem and self-worth, shame, guilt, anger, and grief are common (Fater \& Mullaney, 2000; Isley, Isley, Freiburger, \& McMackin, 2008; Shakeshaft, 2004). Though it is important to remember that sexual abuse is never the fault of the victim, many victims do feel as though they are at fault for their own abuse. Perhaps because of this, many victims fear that other people will find out about their abuse (Fater \& Mullaney, 2000; Isley, Isley, Freiburger, \& McMackin, 2008). Cognitively, victims may have both trouble with intrusive memories about their abuse and difficulty remembering specific parts of the experience (Isley, Isley, Freiburger, \& McMackin, 2008). Finally, some short-term consequences for victims are dependent upon the identity of their perpetrator. Victims may have trouble with other friendships and relationships, particularly if their perpetrator was someone that they trusted and looked up to (Wolfe, Jaffe, Jette, \& Poisson, 2003).

Long-term consequences of CSA victimization are also quite common. These types of consequences can last well into adulthood, impacting victims throughout their lives. Interpersonal long-term consequences of CSA victimization include difficulty developing appropriate relationships, and problems with intimacy in the relationships that they do have (Francis, \& Straatman, 2006; Uliando \& Mellor, 2012; Wolfe). Emotional consequences include helplessness, confusion, fear, 
blunted emotional affect, and difficulty with emotional regulation (Fater \& Mullaney, 2000; Uliando \& Mellor, 2012). Victims may also do what they can to avoid reminders of their abuse (Wolfe, Jaffe, Jette, \& Poisson, 2003). CSA victimization can also include an array of long-term situational consequences, such as poor academic performance (Shakeshaft, 2004), disrespect for authority (Isley, Isley, Freiburger, \& McMackin, 2008), domestic violence perpetration, and involvement with the criminal justice system (Wolfe, Francis, \& Straatman, 2006). Finally, mental health issues such as sleep disorders, psychiatric disorders, depression, panic disorder, PTSD, and alcohol dependence are common for victims of CSA (Carr, Dooley, Fitzpatrick, Flanagan, \& Flanagan-Howard, 2010; Fater \& Mullaney, 2000; Shakeshaft, 2004).

Overall, CSA is a pervasive societal problem that can have severe consequences for victims. To effectively address CSA, it is critical to understand underlying factors that provide a foundation for its perpetration. Rational Choice Theory represents a helpful theoretical framework to provide a context for CSA. The following section describes this theory and explores its relationship to crime perpetration. 


\section{Chapter 2: Rational Choice Theory and Crime Perpetration}

Rational Choice Theory (RCT) represents a theoretical framework often used to explain the perpetration of criminal behavior. As noted above, it provides a helpful framework for contextualizing CSA. This chapter will describe RCT's history, and discuss how it has been utilized in the crime perpetration literature.

\section{Rational Choice Theory}

Rational Choice Theory (RCT), sometimes referred to as the Rational Choice Perspective or the Rational Choice Approach, assumes that people who commit crimes do so because they see it as an effective way to achieve a desired benefit (Cornish \& Clarke, 1986). Within this framework, the commission of crimes is not seen as random or senseless, but as a calculated decision by an individual to obtain a specific reward. The theory suggests that prior to committing a crime, offenders engage in a cost-benefit analysis, taking into account what will need to happen to achieve their goal, as well as the potential for adverse outcomes if they are caught. If the costs for committing the crime are too high, the potential perpetrator may be less likely to commit that crime (Pratt, 2008). Decisions made in regard to the commission of a crime may also be limited by situational factors, such as time, or individual factors, such as the offender's cognitive abilities (Cornish \& Clarke, 1987). Regardless of the context of the crime, RCT assumes that offenders are looking to minimize risks and maximize benefits. As many crimes are not based on a single action, RCT was developed to allow for a dynamic approach, viewing crime as a 
process that takes situational factors into account (Cornish \& Clarke, 1987). Beyond the initial choice to commit a crime, offenders continue to make choices throughout the process of committing a crime, based on situational factors that will minimize risks and maximize benefits. Finally, as individuals commit more crimes over time, they get better at understanding the impact that various decisions will have on their success given a particular set of circumstances. As such, they may begin to adjust their actions to achieve the best possible outcome (Leclerc, Proulx, \& Beauregard, 2009). In this way, their criminal behaviors become more refined, and their decision-making becomes more experience-based.

Many different types of both sexual and non-sexual crimes have been successfully explained within the RCT framework. Some examples are homicide (De Souza \& Miller, 2012), assault (Reynald \& Elffers, 2009; Schreck \& Fisher, 2004), burglary (Groff, 2007), cybercrime (Yar, 2005), domestic violence (Mannon, 1997), sexual offenses involving adults (Beauregard, Rossmo, Kim, \& Proulx, 2007), and the perpetration of child sexual abuse (Leclerc, Wortley, \& Smallbone, 2010). These various applications reflect a number of similarities in the way that many criminals behave and demonstrates that CSA offending is not an exception to the principles described in this theoretical framework. In general, those who choose to commit a crime make decisions based on situational factors that will allow an easier path to successful commission of the crime. Much like a burglar would choose to rob a house where no one is home, and where they are unlikely to be detected by neighbors (Cornish \& Clarke, 1986), those who sexually offend against children are 
more likely to choose a child who is vulnerable, lacks supervision, and unlikely to report the abuse.

Rational Choice Theory has greatly informed research on the perpetration of CSA, as it is easily applied to this phenomenon. RCT's assumption that offenders make a continuing set of decisions across the offending process, from first deciding to engage in a criminal act, through the commission of the crime, and including how to minimize detection following perpetration, is also clearly reflected in offenders' "modus operandi" or pattern of perpetration. The next chapter will discuss how RCT has informed and is reflected in research on the modus operandi of child sexual abusers. 


\section{Chapter 3: Modus Operandi in the Literature}

Definition. Modus operandi is an observable phenomenon defined as a pattern of perpetration that facilitates the commission of CSA as well as minimizing the perpetrator's chances of being detected as an offender (Kaufman et al., 1998; Kaufman et al., 2010). In defining MO as a pattern or a process, it follows that it includes what happened before, during, and after the commission of CSA. Understanding the way in which offenders commit their crimes has been useful in informing both prevention and intervention strategies for CSA offenders as well as victims, and has been a central component in the CSA literature for nearly 30 years. This chapter will describe the MO research that has been conducted in the CSA literature to date.

Leclerc, Proulx, and Beauregard (2009) authored a review article on the MO literature through 2009. To chart the development of MO in the CSA literature, this review will be summarized, and then MO studies since 2009 will be reviewed.

Early Use. Initially, modus operandi was studied as a means of understanding how best to prevent CSA. This was in response to what was perceived as ineffective prevention programming as a result of an anecdotal understanding of the commission of CSA (Berliner \& Conte, 1990). These early descriptive studies (Berliner \& Conte, 1990; Budin \& Johnson, 1989; Christiansen \& Blake, 1990; Conte, Wolf, \& Smith, 1989; Lang \& Frenzel, 1988) are integral in that they highlight the importance of modus operandi as a critical factor for understanding the element underlying CSA and providing directions for the its prevention. At the time, 
however, studies in this area were lacking in methodological rigor. They did not rely on any specific definition of modus operandi, they utilized small samples of participants, and they were predominately qualitative in nature. In fact, the existing research in this area did not include the use of a reliable or valid measure of MO. It is this critical gap that led to the development of Kaufman's (1989) Modus Operandi Questionnaire.

The Modus Operandi Questionnaire. The MOQ (Kaufman, 1989) is the first reliable and valid quantitative measure of MO that examined the full spectrum of offender-victim interactions from an offender's strategies to access a victim through their efforts to maintain their victim's silence following the onset of sexually abusive behaviors. Specifics of the creation and validation of the MOQ will be covered in the next chapter of this document, but it is important to acknowledge the impact that this measure had on the CSA literature at this point in time. Beyond providing a reliable quantitative mechanism with which to measure $\mathrm{MO}$, the questionnaire helped organize thinking about MO by presenting it as a temporal, stage-based process. The temporal stages of CSA included in the MOQ are: (1) Accessing the victim; (2) Gaining the victim's trust; (3) Gaining the victim's cooperation in abusive acts (i.e., through bribes and threats); (4) Details of the victim's abuse; and (5) Maintaining the victim's silence after onset of the abuse. From an RCT perspective, it becomes clear that each stage in the MO process (and the situational factors that influence these stages), inform decisions made throughout the progression of the crime (Leclerc, Proulx, \& Beauregard, 2009). These stages had been uncovered in 
past exploratory research, and a measure that encompasses the entire MO process was an important contribution to the field. The introduction of this scale set the norm for MO being discussed based on temporal stages, even where the MOQ was not utilized in a particular study (Leclerc, Proulx, \& Beauregard, 2009).

Situational Factors. As Rational Choice Theory (Cornish \& Clarke, 1986) suggests, the commission of a crime reflects a decision-making process wherein situational factors are taken into account. As such, it follows that modus operandi is dependent upon these situational factors to shape offending behavior. With this in mind, MO may be considered fluid and adaptable, with offenders adapting their approach based on a combination of factors specific to their own characteristics and preferences, the characteristics of a potential victim, and environmental factors (Lacoste \& Tremblay, 2003). Therefore, MO is most useful when studied in conjunction with variables that help describe these three dimensions. Those offender and victim characteristics most often examined in the research literature include offender age, victim age, victim gender, offender-victim relationship (intrafamilial vs. extra-familial), and offender deviant sexual fantasies. Environmental and contextual variables investigated in the literature include such things as setting characteristics (e.g., child's home, victim's home, organization), type of supervision, and who is providing the supervision (Crosson-Tower, 2005; Leclerc, Smallbone, \& Wortley, 2015). As the focus of this study is to enhance the MOQ for use in predictive research, it is important to review how MO has been used in conjunction with victim and offender characteristics as well as key situational factors. 
Offender Age. Research on offender age has focused on differentiating between adolescent and adult offenders. Offenders are generally considered to be adolescent if they are between the ages of 12 and 18 at the time of their offense, and adults if they are over the age of 18 (Wyatt \& Peters, 1986). Studies that have taken offender age into account tend to focus on one age group or the other, meaning that only a few studies have directly compared the two groups. In one such study, however, Kaufman and colleagues (1998) found that adolescents were more likely to adopt a variety of MO strategies to gain victim compliance in sexual activity, as opposed to their adult counterparts, who used fewer strategies. Juvenile offenders also used a greater variety of silencing strategies, and were more likely to engage in coercive or manipulative MO tactics.

Victim Age and Gender. Two studies examined differences in MO based on victim age (Kaufman, Hilliker, \& Daledien, 1996; Leclerc, Carpentier, \& Proulx, 2006). One main finding was that adult offenders were found to be more likely to use manipulative and persuasive MO strategies with older victims as opposed to the non-persuasive strategies that characterized younger child victims (Leclerc, Carpentier, \& Proulx, 2006). Adolescent offenders reported a greater reliance on alcohol and drugs to groom older victim, but all other MO strategies were most commonly utilized when the victim was in middle childhood, or between 4 and 9 years old (Kaufman, Hilliker, \& Daledien, 1996). This may be because children under the age of four years of age do not have the cognitive abilities to understand various MO tactics, and after nine years of age, victims and adolescent offenders are 
closer to peer status, which may change the way in which offenders operate. In the same study, Kaufman and colleagues (1996) examined victim gender as variable of interest. They found that perpetrators who offended against both males and females used a broad array of manipulative or threatening strategies (e.g., threatening to harm the victim; threatening to end the relationship) more often than their counterparts who may have offended strictly against males or females. Offenders who only abused males or only abused females looked more similar to each other in the MO strategies that they used, meaning that these two groups did not statistically differ in how often they endorsed specific MO strategies.

Offender-Victim Relationship. Another situational variable used to measure differences in MO is the offender-victim relationship. In the literature, the two groups that are most often looked at are intra-familial and extra-familial offenders. Intra-familial offenders are defined as an offender-victim pair that is either related or cohabitates. Extra-familial offenders encompass all victim-offender pairs that are not related and do not live together (Fischer \& McDonald, 1998; Kaufman et al., 1998; Smallbone \& Wortley, 2000). It is important to note that in $90 \%$ of CSA cases, the victim knows the offender (Snyder, 2000; Tofte \& Fellner, 2007).

Kaufman and colleagues have done most of the research on victim-offender relationship and MO. One major finding is that intra-familial offenders may use bribes and enticements in the pre-offense MO stages and threats and coercion in the silencing MO stage more than extra-familial offenders (Kaufman et al., 1996). Extrafamilial offenders are more likely than intra-familial offenders to use drugs and 
alcohol to gain victim compliance to sexual abuse (Kaufman et al., 1998). Through an RCT lens, it follows that offenders will make different offending decisions based on their relationship to the offender, so more research in this realm would be useful.

MO Research Since 2009. Since 2009, work on MO in the CSA literature has both expanded and lessened. Constructs of interest in the literature include work on the MO of female offenders (Wijkman, Bijleveld, \& Hendriks, 2014), internet offenders (Elliott \& Beech, 2009; Kloess et al., 2015), and work linking MO behaviors to context, to complete the understanding of the crime commission process. One example of this is the work on the "hunting" process of serial offenders (Beauregard, Rossmo, \& Proulx, 2007, Rebocho \& Goncalves, 2012). This work explores the behavioral process of serial offenders and clusters, or profiles, the offenders by their offense type. Another line of work has studied offender MO and victim behavior. One such study (Van Gijn \& Lamb, 2013) interviewed victims about their offenders' MO, and found that offenders used both persuasive and coercive strategies, mirroring items on the MOQ. Another victim perspective study looked at a victim resistance scale in conjunction with MOQ data, and linked different types of victim resistance strategies, finding that violent MO strategies led to more resistance than desensitization or gift-giving (Leclerc, Wortley, \& Smallbone, 2010). Finally, modus operandi has been looked at in an organizational context (Colton, Roberts, \& Vanstone, 2012; Firestone, Moulden, \& Wexler, 2009; Leclerc, Proulx, \& McKibben, 2005; Leclerc \& Cale, 2015; Sullivan, Beech, Craig, \& Gannon, 2010). These contexts include churches, schools, and other youth serving organizations. Many of these 
studies have not directly measured MO, but have an interest in how sexual abuse specific to organizational settings functions.

There is much more work to be done to examine how offending patterns may connect with various antecedent variables and outcome variables related to offending. While this chapter discussed past uses of MO in the CSA literature, the next chapter will examine the creation and structure of the MOQ as a basis for further psychometric work. 
Chapter 4: The Modus Operandi Questionnaire: Description and Psychometric

\section{Development}

Since its conception, the MOQ has been through much iteration and has been factor analyzed within the Exploratory Factor Analysis (EFA) framework. As such, this past work will serve as the basis for the current study. This chapter will describe the history and structure of the measure and explain past factor analytic efforts.

History. The MOQ was constructed largely in response to criticism that child sexual abuse prevention programming was based almost entirely on anecdotal evidence and clinical case studies (Conte, Wolfe \& Smith, 1989). While a clear need existed for a better understanding of the strategies that offenders use to sexually abuse children, the literature included mostly descriptive studies with low generalizability due to small sample sizes, and reliance on qualitative methodology (Kaufman et al., 1997). In response to this, Dr. Keith Kaufman created the first version of the Modus Operandi Questionnaire in 1989. This measure was intended for adults who sexually offend against children, with a parallel version for adolescents developed in 1992 (AMOQ). Both versions of the questionnaire included sub-scales based on a specific temporal MO stage. The stages included were as follows: accessing the victim, gaining the victim's trust, bribes and enticements to gain cooperation, threats and coercion to gain cooperation, the actual abuse, and strategies to maintain victim silence. With time, the MOQ and AMOQ were combined, and there is currently one version of the questionnaire that 
is used with both adolescent and adult offenders. Combining these very similar measures was also supported by evidence that both adult and juvenile offenders' MO varied across temporal stages (Kaufman et al., 1997).

Once created, a study was conducted to examine if the questionnaire was a comprehensive way to gather information from an offender when compared to a structured interview (Kaufman et al., 1996). Findings revealed that in most cases, the MOQ was as effective, and in some cases more effective, than structured interviews for identifying MO strategies. The one exception was that the structured interview was found to be better at soliciting offender information about threats and coercion to gain cooperation. In general, however, this study established the utility of the pencil-and-paper questionnaire for obtaining MO related information and its superiority over interview approaches on many MO dimensions. This study, as well as work on the measures' content validity, encouraged the use of these MO measures for large-scale data collection with CSA offenders.

Description. The MOQ differs from other scales in that it was created to bridge the gap between descriptive and predictive research. It is intended to be utilized to examine the various temporal dimensions that, as a whole, constitute the full continuum of MO behaviors. While the questionnaire has a large number of items (339 in the version used in this study), it reflects six subscales of more moderate length. Items are behaviorally specific (e.g., "Giving them [the victim] alcohol;" "Saying you will take them places") and meant to be analyzed within the context of their scale which reflects the temporal dimension (e.g., offering a child a 
gift [the MO behavior] to obtain their cooperation in sexually abusive acts [the temporal stage of the abuse process]) and not across the questionnaire as a whole. The framework of RCT asserts that stages of MO are qualitatively different. This suggests that the goal of one stage in the abuse process may be different from another (e.g., accessing a victim vs. maintaining victim silence following abuse onset) while later stages remain dependent upon the offer's success in an earlier stage (i.e., the opportunity to engage in later abusive acts may be dependent on first obtaining a victim's trust). In some cases, very different MO strategies may be used in different stages of the CSA process. For example, an offender may use pro-social MO strategies, such as showering a victim with gifts and compliments, to gain cooperation, and then rely on more threatening strategies to maintain silence if a victim threatens to tell someone about the abuse. Since clinical and research evidence suggests that the MOQ stages reflect critical, real world temporal dimensions in a CSA offending process, the psychometric focus on the MOQ has always been at the level of examining the scales within each temporal stage. As such, the MOQ may be seen as a series of scales (composed of factors) that reflect the CSA process. Conceptualizing the measure in this manner has allowed for its clinical use as well as its frequent inclusion in research studies of CSA (Kaufman et al., 1997).

Past Analyses. A previous factor analysis has been conducted on four sections of the MOQ. Though this analysis is not comprehensive, it is relevant to the current study, so it will be reported in the following section. 
The four sections analyzed are: (1) Gaining trust, (2) Bribes and enticements for cooperation, (3) Threats and coercion for cooperation, and (4) Maintaining silence. An iterated principal axis factor analysis, using squared multiple correlations as prior communality estimates was conducted for all of the items within each of the above scales separately. Sub-scales for each scale were derived based on items that loaded onto each factor.

The strategies for "Gaining trust" scale provided an interpretable 3-factor solution, which accounted for $41.58 \%$ of the scale's variance. The sub-scales derived were: (1) Love, attention, and gifts (22 items), (2) Drugs and alcohol (4 items), and (3) Trust by association (7 items). The eigenvalues for these scales were calculated at 11.06, 3.05, and 2.11, respectively. The first scale, Love, attention, and gifts, was made up of MO strategies that made victims feel special, loved, and appreciated (e.g., "giving them a lot of attention.) The second scale, Drugs and alcohol, included items describing perpetrators allowing their underage victims to use drugs and alcohol (e.g., "letting them smoke cigarettes"). The third scale, Trust by association, included items that indicated the perpetrator used credibility through friends and family to gain trust (e.g., saying you know one of their parents"). The internal consistency of these sub-scales was good (.81-.93).

The next scale, "Bribes and enticements for gaining the victim's cooperation," provided a 4 -factor solution with $41.2 \%$ of the variance explained. The scales were: (1) Desensitizing the victim to sexual contact (16 items, e.g., "talking more and more about sex"), (2) Use of pornography (8 items, e.g., "showing them magazines, 
pictures, or videotapes with naked children in them"), (3) Drugs and alcohol (3 items, e.g., "giving them drugs"), and (4) Giving gifts and privileges (11 items, e.g., "giving them money from time to time"). Eigenvalues for these factors were 11.98, $3.74,2.32$, and 1.74 , respectively. The internal consistency of these subscales was good (.83-.92), as well.

The next scale, “Threats for gaining the victim's cooperation," provided a 5factor solution, which explained $44.11 \%$ of the variance. The scales derived include (1) Threat to harm others (6 items, e.g., "saying you will hurt their mother"), (2) Threat to kill victim or others (6 items, e.g., "saying you will kill them"), (3) Helpless (9 items e.g., "saying you would tell on them about having sex with you"), (4) Drugs and alcohol (3 items "getting them drunk with beer or liquor"), and (5) Threat to hurt victim (4 items "saying you will hurt them with a gun"). Eigenvalues for the scale were given, but only for four of the five scales with no indication of which scale was left out. Internal consistency for these scales was decent, ranging from .78 to .89 .

The final scale, "Maintaining silence," provided a 2-factor solution, which accounted for $35.19 \%$ of the total variance. The first scale was Benefits/consequences for victim and offender (21 items, e.g., "saying you would take them places if they didn't tell anyone") and the second was Threat/harm to victim or others (14 items, e.g., "saying you would hurt their mother"). Eigenvalues for these two scales were 8.51 and 5.46 respectively, and internal consistency was $\operatorname{good}(.86-.89)$. 
Change Over Time. Since this analysis, some changes have been made to the MOQ. First, a few items have been added or changed. Second, when this factor analysis was conducted, participants rated how often they used each specific strategy on a 7-point Likert scale ( $1=$ not at all; $7=$ almost always). In the iteration of the MOQ used for this study, participants rated each item on a 4-point Likert scale $(0=$ never; $4=$ almost always). The change in the scale was prompted by recognition that respondents rarely used all seven of the Likert anchors on the scale. Finally, portions of the scale have never been factor analyzed, including information on how offenders access their victims, information about how offenders relate to their victims prior to abuse, and information about the actual abuse.

This section discussed the reasoning behind the creation of the MOQ, its validity in comparison to structured interviews, and the factor structure of four of the MOQ scales that have been subjected to an exploratory factor analysis. The next section will discuss the utility of MO and the MOQ in clinical work, prevention, and research. 


\section{Chapter 5: Modus Operandi and Prevention}

The MOQ provides researchers with a mechanism to investigate CSA offender modus operandi in an empirical and generalizable fashion, which has obvious implications for the construct of MO in offender research. As MO is an applied construct, it is also important to discuss the impact that MO research has both on sex offender assessment and treatment as well as on CSA prevention. This chapter will discuss the literature on the practical implications of understanding offender MO, and make a case as to why more empirical research is needed.

\section{The Public Health Model of Prevention}

Though treatment and prevention are often described as different constructs in the CSA literature, both can be conceptualized as part of the Center for Disease Control's Public Health Model of Prevention (Centers for Disease Control and Prevention, 2004). This approach focuses on the overall health of the population, instead of focusing on the health of any one individual. The most recent CDC Public Health Model is focused on a four-step approach to violence prevention. These steps include: (1) Defining the problem; (2) Identifying risk and protective factors; (3) Developing and testing prevention strategies; and (4) Assuring widespread adoption (Centers for Disease Control and Prevention, 2004).

The model also breaks prevention down into three levels: Primary/ Universal, Secondary/ Selected, and Tertiary/ Indicated. These levels are the "who," explaining what part of the population that the program will be targeted for (i.e., everyone, high risk individuals, individuals who have been victims or perpetrators). 
They are combined with a "what," or a level describing where the problem will be targeted for intervention. The four levels are Individual, Relationship, Community, and Societal. The Individual level indicates that the problem is within specific individuals, and interventions are targeted at individuals. The Relationship level indicates that the problem is within a dyadic or small group relationship, and interventions are targeted here. The Community level indicates that the problem is within a community, such as a neighborhood or organization. Interventions are targeted toward communities as a whole. Finally, the Societal level indicates that the problem is with macro-level factors, such as gender inequality or economic inequality. Interventions are designed to target these larger factors (Centers for Disease Control and Prevention, 2004).

These three "who" levels (Primary, Secondary, Tertiary) are applicable to the prevention of CSA, and can benefit from research on MO. Primary prevention is defined as having the goal of preventing a problem before it begins (Centers for Disease Control and Prevention, 2004). Programs at youth-serving organizations that educate parents and children about the MO of CSA offenders classifies as a form of primary prevention. Secondary prevention efforts target individuals who are at risk of a problem, and intervene before the problem occurs or worsens (Centers for Disease Control and Prevention, 2004). Internet programs that direct people searching for potential child pornography, such as photographs of naked children, to resources where they can get help, classifies as form of secondary prevention. Finally, tertiary prevention takes place after a problem has occurred, and attempts 
to stop that problem from reoccurring (Centers for Disease Control and Prevention, 2004). Treatment for CSA offenders with the goal of preventing recidivism is an example of tertiary prevention of CSA. Understanding MO has been useful for all types of prevention.

Understanding modus operandi, and utilizing measures such as the MOQ, is helpful in all three mentioned prevention areas. For primary prevention, it is helpful for groups such as parents, youth serving organization staff, and children to understand the MO tactics that offenders use, as a means to stop abuse before it begins. Similarly, secondary prevention benefits from understanding MO. If a child was being groomed by an offender, and at risk for abuse, recognition of this pattern could also be helpful in intervention. Finally, offenders in treatment can benefit from understanding their own MO tactical patterns, and utilize this knowledge to stop themselves from re-offending.

\section{MO and Clinical Treatment}

One form of tertiary CSA prevention is clinical treatment of those who have sexually abused children. Kaufman and colleagues (1998) assert that it is important for therapists treating offenders to clearly understand the offenders' typical MO patterns. These insights allow clinicians to target treatment to the types of issues that are reflected in an offenders' particular MO. In some cases, an offenders' MO may reflect difficulties with arousal to younger children that must be addressed or concerns about the connection between violence and sexual arousal. For all CSA perpetrators, knowing about an offenders' patterns of perpetration (MO) provides 
information that can be shared with family, friends, and probation officers to enhance safety planning and to identify "red flag" indicators of an offender engaging in behaviors that may be leading them back toward an offense (i.e., Relapse Prevention efforts; Marques et al., 2005). This is especially relevant due to the number of MO strategies that can be described as pro-social behavior (e.g., complimenting a child, buying a child gifts). While the intent of these pro-social strategies can be both altruistic and malicious, it is helpful for an offender in treatment and their clinician to recognize when these pro-social strategies are being used with the intent to harm. In his work with Rational Choice Theory, Cornish (1994) stresses that understanding the full crime commission process allows multiple points of intervention. Clinical recognition of a CSA offender's typical MO pattern can aide with early intervention if and when the offender begins the crime process with another victim.

Understanding MO in the context of offender treatment can also inform tertiary prevention efforts designed to utilize situational barriers to offending as a strategy to prevent reoffending (Leclerc, Proulx, \& Beauregard, 2009). The authors describe how many offenders encountered situational obstacles that either prevented or slowed their crime commission. It is argued that therapists could identify these obstacles within specific modus operandi stages and proactively help the offender and their support system put similar obstacles in place to prevent reoffending. For example, if an offender has previously utilized pornography to desensitize their victims to sexual content, technology that blocks pornography on 
the internet and television at the home of an offender could offer a significant barrier to the offender utilizing this victim grooming strategy in the future.

Finally, MO is also a useful construct in treatment for CSA victims. A common reaction to victimization is guilt, powerlessness, and self-blame for the abuse (Fater \& Mullaney, 2000; Isley, Isley, Freiburger McMackin, 2008; Shakeshaft, 2004). This can be interpreted to mean that the experience of being sexually abused can lead to a victim feeling quite disempowered. It has been suggested that using treatment to help victims understand the crime commission process that they were subjected to could allow them to understand that they did not do anything to deserve the abuse, and that the abuse was not self-inflicted (Kaufman et al., 1998). It may also be empowering for victims to understand the strategies that were used by their offender, so that they may recognize these patterns and report them quickly if they ever experience similar MO strategies (Berliner \& Conte, 1990). While it should be consistently stressed that sexual abuse is never the fault of the victim, there is evidence that CSA victimization is a risk factor for sexual and other types of victimization as an adult, and this connection is stronger if the CSA victim experiences a great deal of psychological stress (Cuevas et al., 2010; Desai et al., 2002). Helping victims better understanding the crime commission process and how MO strategies were used to "set them up" may minimize self-blame and psychological stress. It is possible that this type of treatment could be beneficial for the victim throughout their lifespan. 


\section{MO and Prevention}

While tertiary prevention strategies are important in preventing further occurrences of CSA, primary prevention strategies may be able to stop instances of CSA from ever occurring. One way of conducting primary prevention of CSA is with the use of situational prevention.

The Situational Prevention Model (SPM, Cornish \& Clarke, 2003) suggests that crimes occur due to contextual factors that strengthen opportunities for crime to occur. This follows Rational Choice Theory, but places more emphasis on the role of context, and the consideration of how context can be altered to deter crime from occurring. This altering of context can relate both to reducing the opportunities to commit a crime (Cusson, 1993) and reducing the motivation that individuals have to commit a crime (Wortley, 2001). In other words, situational prevention works by making it more difficult for an offender to commit a crime, and making them less motivated to commit the crime.

A promising iteration of the SPM is the Situational Prevention Approach (SPA), which has been used in youth serving organizations to prevent CSA (Kaufman, Mosher, Carter, \& Estes, 2006). This model has two main purposes. First, it gives organizations a means to systematically assess their situational risks that may increase the likelihood of CSA occurring. Second, it gives a mechanism to match risks with prevention and risk reduction solutions (Kaufman, Hayes, \& Knox, 2010). The SPA focuses on a core Crime Opportunity Structure of victim characteristics (both of the individual and their family context), target locations, and 
facilitators (factors that increase the chances of abuse occurring). It also pays attention to routine activities, the larger physical environment, and climate and norms (Kaufman, Hayes, \& Knox, 2010). The SPA has been used successfully in Boys and Girls Clubs of America, and is currently being piloted on college campuses.

When thinking about appropriate situational strategies to prevent CSA, it is helpful to understand the MO of CSA offenders. Though the SPA is one example of a CSA prevention program that works in organizations, it should be noted that there is not a "one size fits all" approach to CSA prevention (Kaufman et al., 2006), so programs should be created to address various offender-victim-environment interactions. This is where knowledge of context-specific modus operandi strategies becomes necessary. Knowing that different strategies may be utilized depending on contextual factors such as victim age, offender age, or victim-offender relationship (Kaufman, Hilliker, \& Daleiden, 1996), more work to understand these nuances is necessary to continue development of prevention programs that are appropriate for the wide array of contexts in which CSA occurs (Kaufman et al., 2006).

Though it is not difficult to understand the importance of utilizing information about MO in the construction of primary and tertiary prevention programming, it is evident that the field could still utilize more information on the differences in MO based on contextual factors, both within and across MO stages. The next chapter will discuss what is still missing from the literature, and explain why a re-examination of the MOQ can strengthen future research. 


\section{Chapter 6: Literature Critique and Justification for the Current Study}

While the importance of understanding modus operandi within the context of CSA prevention has been shown, there is a limited amount of research that explores the construct of modus operandi and utilizes the MOQ. Currently, much of the literature on CSA perpetration focuses on situational aspects of offending, and the crime commission process. While MO is still a factor in this literature, a search for journal articles looking at MO and CSA since 2013 showed that the MOQ has become less often utilized to collect MO data in the past five years. Though the MOQ is acknowledged as the basis for much of the research on MO within CSA today (Lasher, McGrath, \& Cumming, 2014), researchers are relying on other means to get MO data, which include other quantitative measures, as well as qualitative methods such as interviews (Gonultas \& Sahin, 2016; James \& Proulx, 2016; Kloess et al., 2015; Leclerc \& Wortley, 2015). In the one study that has utilized the MOQ since 2013 , only descriptive data, in the form of percentage of the sample that used each specific strategy, was reported (Leclerc \& Felson, 2016).

In their 2009 review of the CSA MO literature, Leclerc, Proulx, and Beauregard stress the importance of more MO research being conducted, particularly in conjunction with situational factors. They agree with the assertion that MO is an important factor in the understanding of both crime commission and prevention, and state that we do not yet know enough about the construct. In particular, they describe the need to do research on the MO stage of committing the actual abuse. As of now, the MO literature does not explore the relationship 
between MO strategies, situational factors, and the actual abuse. The authors also suggest that it could be useful to examine the relationship between MO and location based factors, such as where the abuse takes place, and where a victim is accessed. This is useful to see if place-based situational factors influence different types of MO strategies. It is important to note that much of this research has not been conducted since 2009, and what has been studied has not involved use of the MOQ.

The MOQ has been mainly used to examine group differences in MO (Kaufman, Hilliker, \& Daleiden, 1996; Kaufman et al., 1998; Kaufman, Wallace, Johnson, \& Reeder, 1995) and to conduct descriptive offender research (Leclerc \& Felson, 2014). Current work on crime commission pathways and situational factors in offending relies on other methods of collecting MO data (Gonultas \& Sahin, 2016; James \& Proulx, 2016; Kloess et al., 2015; Leclerc \& Wortley, 2015). This may be because the MOQ has not been validated using the most up to date methods. Specifically, all factor work on the MOQ has been done in an exploratory framework, and some sections of the questionnaire have never been factor analyzed. Finally, even though the MOQ is described as a temporally based measure, the "Gaining cooperation before abuse" sections are broken up into two different scales, based on strategy type (i.e., "Bribes and enticements" and "Threats and coercion"). This is inconsistent with the stage-based model, as bribes and threats to gain cooperation could happen simultaneously. As the MOQ has been universally recognized as the formative measure for studying MO in the CSA literature, and has framed the research on MO that has followed its creation, it is likely that with a few updates, the 
MOQ could once again be utilized to its full capacity, and help formulate research that can better inform the prevention of CSA.

A few changes can be made to update the MOQ. First, the scale can be reconceptualized as a true reflection of the temporal model of crime commission that it was based upon. This means that it is important to analyze the Bribes and Enticement and Threats and Coercion sections together, making a new "Strategies to Gain Cooperation" scale. This will theoretically show that these strategies can happen at the same point in time, and are not part of separate MO constructs.

Second, the factor structure of the MOQ scales can be analyzed under a confirmatory framework using structural equation modeling (SEM), to analyze the current fit of the factor structure. This will allow each scale to be described as a second-order latent factor, with first-order factors representing the sub-scales. The items on the MOQ are manifest indicators of the latent constructs they represent. This framework will allow the use of model fit statistics to examine how well the behavior-based indicators represent the latent MO stage. Correlations between scales and sub-scales can also be examined for convergent and discriminant validity, and the reliability statistic alpha can be calculated for all factors.

Finally, as suggested by Leclerc, Proulx, and Beauregard (2009), previously unexamined sections of the MOQ can be analyzed. This includes a section about accessing victims, relating to the victim prior to abuse, and behaviors within the sexual abuse. Showing how these constructs can be analyzed will add to the literature, as it will allow the MOQ to give input into every stage of the crime 
commission process. Understanding what factors exist within these constructs will help to understand how they can be utilized in further research.

A fresh psychometric analysis of the MOQ could help re-introduce the measure into the CSA literature. It can be further utilized as part of studies that explore the relationships between MO strategies and situational factors, as well as studies that connect the temporal MO stages to examine crime commission pathways. These types of studies are essential to the continued work on the relationship between the ways that offenders offend, and how this offending can be prevented.

As such, this study describes a psychometric analysis of the MOQ that revisits exploratory factor work for each MO stage on the measure, moves the analysis of the MOQ measures into the confirmatory framework, and provides reliability statistics for each scale and all subscales. This was be done using a large-scale data set, where over 800 juvenile and adult offenders completed the MOQ. In the next section, methodology for this study will be described. 


\section{Chapter 7: Methodology}

\section{Participants}

The data used for this study is part of a larger, ongoing investigation on CSA offending conducted by Dr. Keith Kaufman and colleagues. Modus operandi data is one part of the collection, which also includes supervision data, and cultural data (supported by CDC Grant R49/CCR016517-01). The groups that were surveyed as part of this study were both adolescent and adult offenders, caregivers of both CSA

offenders and victims, and a number of control groups. These control groups include adolescents with no offense history and their caregivers, adolescents who have committed non-sexual offenses and their caregivers, adults with no offense history, and caregivers of youth who have not perpetrated or been a victim of sexual offenses. This study utilizes a small portion of this data, focusing only on adolescent and adult sexual offenders.

The offenders include 854 adolescent and adult offenders who were recruited from correctional facilities and outpatient treatment programs in Oregon, Washington, Texas, South Carolina, New York, Florida, Ohio, Connecticut, and New Jersey. Of the 854, 360 were considered adult offenders, meaning that they committed their offense at the age of 18 or older. The other 368 offended before the age of 18. An additional 76 indicated offending both as a juvenile and as an adult. At the time that the questionnaires were completed, the average age of the adult offenders was $(M=40.43, \mathrm{SD}=11.82)$ and the average age for juvenile offenders was $(M=16.77, \mathrm{SD}=2.27)$. Finally, $56 \%$ of the participants committed an intra-familial 
offense, meaning that the victim either lived with or was related to the offender. The other $44 \%$ committed an extra-familial offense, meaning that the victim was both unrelated to the perpetrator and did not live in the same home. Of the 854,50 will be excluded for being female (11), or completing their packet in Spanish (39).

\section{Design}

This study will examine the psychometrics and factor structure of the Modus Operandi Questionnaire (MOQ). It is cross-sectional and non-experimental, as participants only completed the MOQ once, in one sitting at their correctional facility. Data from this measure will be analyzed for exploratory factor structure, confirmatory factor structure, and reliability.

\section{Measures}

The MOQ is a 339-item self-report questionnaire developed with input from CSA offenders, victims, law enforcement professionals, and treatment professionals. It examines offenders' modus operandi through temporal stages of the CSA process including: (1) Where You Found and Had Time Alone with Children You Abused; (2) How You Gained the Trust of the Children You Abused; (3) About the Time Before The Sexual Abuse Began; (4) Questions About the Sexual Abuse; (5) Ways of Getting the Children you Sexually Abused Involved in Sexual Activity; (6) Threats to Get The Children you Sexually Abused Involved in Sexual Activity; and (7) Keeping the Children Quiet About the Sexual Abuse.

Participants were asked to respond to each question using the victim(s) that would allow for the most MO information. This was defined by four questions, 
asking how many male and female victims were offended against, and what age group they were in (over or under 12). The group with the most victims was the group that the participant was instructed to think about when responds to the questionnaire. Of course, if the participant only had one victim, he responds for that victim. Each item on the questionnaire was examined in terms of frequency, with participants using a 0 (never) to 3 (almost always) Likert-type scale to assess how often they used a particular MO strategy with their most recent victim.

\section{Procedure}

All of the participants were chosen from within a correctional facility or outpatient treatment center. CSA offender status was determined based on the crime for which a person was incarcerated. All who had been incarcerated for committing any type of CSA were invited to participate in the study. Participants over the age of 18 completed informed consent forms, which ensured anonymity and confidentiality. Participants under the age of 18 who reside in a correctional facility are considered to be under the legal custody of facility representatives. As such, facility directors filled out consent forms for youth participants. Then, youth participants were read assent forms, assuring confidentiality and anonymity, and provided assent this way. Participation was voluntary, and participants were aware that they could stop the study at any point.

Prior to survey completion, potential participants were screened for reading ability and comprehension, as well as significant mental disabilities. This involved having facility staff identify offenders who had reading and/or comprehension 
difficulties. If a participant was deemed appropriate for participation, and gave consent, he was given the paper and pencil questionnaires to be completed in one sitting. Besides the MOQ, participants completed a Demographics questionnaire and a Supervision questionnaire. Once completed, participants gave their materials to a research assistant who returned the packets to Portland State University, where they are held in a cabinet behind a locked door.

\section{Description of Analyses}

The analysis for each MOQ temporal scale has three parts. First, an Exploratory Factor Analysis was conducted to obtain a basic idea of the structure of each scale. Then, using this exploratory data, a Confirmatory Factor analysis was conducted using the AMOS package for Structural Equation Modeling in SPSS. Finally, reliability statistics were calculated for each scale and subscale based on the CFA results.

As the Rational Choice Perspective of modus operandi asserts that each temporal stage in MO is qualitatively different from other stages, no attempt was made to factor analyze the MOQ as a whole at this time. Instead, the three-part analysis process for this study was repeated for each of the five temporal scales. The scales analyzed are: (1) Accessing the victim (items 49-81; 84-111); (2) Gaining the Victim's Trust (items 118-158; 161-168); (3) Gaining the Victim's Cooperation (items 218-264; 265-298); (4) The Sexual Abuse (items 175-193; 195-204); and (5) Silencing after the Abuse (items 300-337). The items that are not included have been removed due to their qualitative nature, because they do not describe an MO 
behavior, or because they were not answered by large sections of respondents (over 95\%). This is relevant for questions in the "Accessing" stage that are left out due to only being answered by extra-familial offenders.

There has been debate over whether or not it is appropriate to conduct an EFA and a CFA on the same sample, however, the analysis plan for this study will follow the statistical approach suggested by Van Prooijen and Van Der Kloot (2001), who suggest that this method is not only appropriate, but also necessary. Their reasoning begins with the observation that the EFA is a data-driven model, while the CFA is theory-driven. For this reason, the CFA represents a more restrictive framework, and models that fit a specific EFA may not fit the same model within a CFA framework. The authors suggest that if a model does not fit under both methods of analysis with the same sample, it is unlikely that the factor structure can be replicated with a new sample. As the MOQ has never been analyzed via Confirmatory Factor Analysis, an EFA and a CFA will be conducted for each temporal scale, to examine whether a final CFA model can be assumed replicable with a new sample.

Though past EFAs have been conducted on the scale, they were not used to restrict the factors that can be found in this analysis. In particular, there are two changes that were made to the structure of the MOQ data entered into the EFA to enhance the utility of the model. First, the two gaining cooperation scales (i.e., the use of "Bribes and enticements" and the use of "Threats and coercion") were combined to allow for a more robust examination of the factor structure for all of 
the gaining cooperation items. Second, while the original version of the MOQ used a 7-point Likert scale, this was amended to a 4-point Likert scale due to limited endorsement of item response categories on the original, longer Likert scale. Past EFA work is useful for comparison purposes, but was not utilized to restrict factors for any of the new analyses.

Prior to inferential analyses, descriptive tests were conducted to examine the normality of the data within each scale, as well as how frequently each item within each MOQ scale has been endorsed. All of the items on the MOQ are low base-rate, with only 46 of the 339 having a mean above 1 on a 0 to 3 Likert Scale, indicating positive skew. Many items have such low endorsement rates that over $95 \%$ of the sample indicate that they never used this tactic. These items, listed in Table 1, were removed from further analyses. Table 1 lists the item, the stage-based scale it comes from, and the percentage of the sample that indicated they never utilized the MO tactic.

Next, an Exploratory Factor Analysis using SPSS Software was conducted for each of the five temporal scales. Strict rules for sample size regarding EFA are no longer in practice, and the majority of existing studies reflect a 10:1 participant to item ratio or less, with about one-sixth of the studies analyzed in the paper having a 2:1 ratio or less (Costello \& Osborne, 2009). With 854 participants, and the largest scale being 79 items, the MOQ is beyond a 10:1 ratio of participants to items. For each stage-based scale, the first EFA was conducted with no constraints on the number of factors retained, and utilized an oblique rotation. This decision is based 
on past exploratory factor work on the MOQ (Kaufman et al., 1997). Results were interpreted first by extracting factors with an eigen value above 1.0 (Kaiser's Criteria, 1959). This initial solution was used to test more parsimonious, constrained solutions for each stage. Consideration in the final solution was given primarily to the percentage of variance explained, followed by interpretable factors and Scree plots. Solutions were judged as competent if they explained a majority of the variance (at least 50.1\%), were parsimonious, and were made up of easily interpretable factors.

Once factors were extracted, loadings and cross-loadings were examined. Following Tabachnik and Fidell's (2001) guidelines, items that reached a .3 loading will be considered part of that factor. Cross-loaded items are considered part of the factor onto which they load more strongly. Loaded items were examined qualitatively, and factors were named based on items with the largest loadings, as well as an examination of low loadings (Gorsuch, 1990). Correlations between factors were also calculated and reported in Tables 2-5. This process was repeated for each of the five temporal MO scales.

After the EFA was completed for each scale, a CFA using the AMOS package in SPSS was conducted for each scale. Following the suggestion of Van Prooijen and Van Der Kloot (2001), the exact factor structure that is determined by the EFA was tested for each of the five temporal scales. Models were estimated and identified using Kilne’s (2011) guidelines. Kline also discusses whether item-level or sub-scale level data works better as observed indicators in a CFA model. Generally, CFA 
models are more accurate with indicators being continuous scale scores, and not Likert-type individual items (Harris, 1995). Item-level data can be "noisy," and may be better suited to Item Response Theory tests. However, as these CFAs were based off of EFAs, which are done at the item level, the CFAs for this study were done at the item level.

Van Prooijen and Van Der Kloot (2001), suggest testing items with low factor loadings by both constraining them to 0 , and then allowing some to differ from 0 . However, items in this analysis that load onto factors at below .3 during the EFA analysis stage were qualitatively different than other items on that factor. For this reason, they were not included in the CFA analyses. It is also suggested that factors in a model are allowed to correlate, but this process includes all first-order factors being predicted by a second order factor. For this reason, it seems redundant to also test correlation of first-order factors, with the exception of the silencing model, which only produced a two-factor structure. So, the CFA model tested for all scales is an un-constrained replica of the EFA results, allowing information on the strength of the loadings of first order factors onto the second order factor, as well as the overall fit of that data to the chosen model.

For each stage-based CFA model, the fit statistics of $\chi 2$, the Comparative Fit Index (CFI; Bentler, 1990), Normed-fit Index (NFI, Bentler \& Bonnet, 1980) and Root Mean Square Error of Approximation (RMSEA; Steiger \& Lind, 1980) were examined. According to Hu and Bentler (1999), a score of .95 or above on the NFI or CFI indicates excellent model fit, as well as an RMSEA of .06 or less. 
Finally, reliability statistics were calculated for each of the five temporal stage-based scales and factor-based sub-scales resulting from the CFA. Chronbach's (1951) alpha is a method typically used for measuring subscale's internal consistency reliability when the scale has used a Likert-type response format. It is a "weighted standard variations mean obtained by dividing the total of the $\mathrm{k}$ items in the scale, by the general variance" (Thorndike et al., 1991). As alpha is utilized most often in psychological research, it is the reliability index chosen for this study. 


\section{Chapter 8: Results}

Results will be reported within each stage-based MO scale, indicating EFA, CFA, and reliability findings. This way, the results and analytic process can be easily understood within each stage-based scale. A discussion of the overall findings can be seen at the end of this chapter.

Stage 1: Offenders' Access To Victims. The best EFA model for the 53 items on the Accessing scale is a five-factor model, which explains $41.99 \%$ of the scale's variance. Seven items did not load strongly onto any of the five factors, and were removed from further analyses. A Scree Plot for this scale is provided in Figure 1, and correlations between the factors can be seen as Table 2 .

The first factor is made up of 14 items, which describe ways in which perpetrators build relationships with their victims as a way of accessing them. Therefore, this factor is called "Relationship Building." Example items are "tell them you will do something fun" or "tell them you can be trusted." All items on this factor, as well as their loadings, can be seen on Table 6. One item on this scale, "tell them they would get in trouble if they did not go with you," cross-loaded onto the violence factor $(-.330)$. However, the loading onto this factor was much stronger $(.555)$, so the item remains part of this factor.

The next factor on the Access scale is made up of 8 items that describe the use of violence to access victims. Accordingly, this factor is called "Violence." Example items include "hurt them" and "get angry or violent with them." Interestingly, as seen on Table 6, all of the loadings on this factor are negative. This 
could be because the underlying factor is actually non-violence, or due to the oblique rotation utilized for this analysis. According to Tabachnick and Fidell (2001), an oblique rotation can sometimes reverse the direction of the dimension, as well as the signs of that dimension. At this time, the factor will still be called "Violence," but the negative loadings should be noted, and may indicate that offenders who use violence to access their victims are a different population than those who use other strategies.

The third factor on the Access stage scale is made up of 12 items that describe offenders taking the victims places as a means to access them. Accordingly, the factor is titled "Going Places." Sample items include "take them to parks" and "go to the shopping mall." All items on this factor, as well as their loadings, can be seen on Table 6.

The fourth factor related to accessing victims is composed of 10 items that describe a perpetrator engaging in care-taking behaviors to access their victims. It is likely that this factor describes behaviors used by intra-familial offenders, or other types of guardians. The scale is called "Caretaking," and includes items such as "tuck them into bed," and "give them a bath." All items on this factor, as well as their loadings, can be seen on Table 6.

The final factor on the Accessing scale is made up of two items, both of which are related to cigarettes and alcohol. Of note is that all other items that had to do with giving victims drugs, across all scales, were removed due to extremely low endorsement rates (Table 1). However, this scale was titled "Cigarettes and 
Alcohol," and included the items "Give them cigarettes" and Give them alcohol." The loadings for these two items are provided in Table 6.

Next, the CFA was conducted for the Access scales, replicating the EFA model described above. The resulting model is presented in Figure 2. All five of the firstorder factors load strongly onto the second-order factor, with the standardized estimate for Relationship building being .816, Violence being .557, Going places being .673, Caretaking being .648, and Cigarettes and Alcohol being .388. This indicates that all five first-order factors are good indicators of the accessing stage. The overall model fit for Accessing was mediocre. The chi-square statistic was quite high, at 4798.115. The CFI and NFI both indicate poor fit, at .754 and .711 respectively. The RMSEA indicates good fit, at .066, with a 90\% confidence interval ranging from .064 to .068 . All standardized and unstandardized loadings for this model can be found in Table 7.

Finally, reliability statistics were calculated for all Accessing factors. The Relationship building scale has a Chronbach's alpha of .879. The Violence scale has an alpha of .861. The Going Places scale has an alpha of .877. The caretaking scale has an alpha of .788. Lastly, the Cigarettes and Alcohol scale has an alpha of .466. This indicates that with the exception of the Cigarettes and Alcohol scales, all scales have good internal consistency reliability.

Stage 2: Gaining Trust. A six-factor solution was best for the 47 items included in the EFA for the Gaining Trust stage-based MO scale. This solution explains $53.43 \%$ of the scale's variance. Four items did not load strongly onto any 
factors, and were removed from further analyses. A Scree Plot for this analysis can be seen as Figure 3, and correlations between factors are displayed in Table 3.

The first factor determined by the EFA is made up of 12 items that describe the perpetrator treating their victims with kindness. As such, the factor is called "Kindness," and is made up of items such as "give them a lot of attention," and "do what they like to do." All items on this factor, as well as their loadings, are displayed in Table 8.

The next Gaining Trust factor is composed of 9 items that describe perpetrators efforts to establish themselves as trustworthy through associations with others known to the victim. Therefore, the factor is names "Trust By Association," and is made up of items such as "say you know one of their friends," and "have their friend say to trust you." All items on this factor, as well as their loadings, are provided in Table 8.

The third factor is composed of three items, all having to do with cigarettes and alcohol. Therefore, the factor is named "Cigarettes and Alcohol." An example item is "give them cigarettes," and loadings for all three items are provided in Table 8.

The next Gaining Trust factor is made up of 9 items that describe bribing the victims with gifts or privileges to gain their trust. The factor is therefore named "Bribes." It is important to point out that much like the Violence factor on the Accessing scale; all of the factor loadings here are strong, but negative. Again, this could have to do with the oblique rotation (Tabachnik \& Fidell, 2001), but it could 
also be that offenders who used visible trust-gaining strategies, such as bribes, are different than those that use more interpersonal strategies that can only be seen by the victim. Either way, it will referred to as the "Bribes" scale. Sample items include "give them toys," and "give money to others in their family." All items on this factor, as well as their loadings, are presented in Table 8.

The fifth factor on the gaining trust scale is made up of three items that insinuate manipulating the victim in order to gain their trust. Therefore, the factor is called "Manipulation." Example items include "act like someone they like or trust," and "pretend to be their friend before sexual abuse." All items on this factor, as well as their loadings, are presented in Table 8.

The final factor, composed of seven items, describes behaviors reflecting the perpetrator's attempts to treat the victim as a peer or an equal. Consequently, the factor is named "Treat Like A Peer," and includes items such as "treat them like adults," and "tell them personal things." There is one cross-loaded item on this factor, which also loads onto the "Kindness" factor (.367). It loads onto this factor slightly more strongly (.413), so will remain here. All items on this factor, as well as their loadings, are presented in Table 8.

Next, a CFA was conducted replicating the structure found in the EFA. A model of the CFA can be seen in Figure 4. Five of the six first-order factors load strongly onto the second order factor, Gaining Trust. The strong standardized loadings are as follows: Kindness loads at .883, Trust By Association at .593, Bribes at .857, Manipulation at.613, and Treat Like A Peer at.976. Cigarettes and Alcohol, 
however, does not have a strong loading, at only .195, indicating that this may not be a good representation of gaining trust. While the path is significant at the .01 level (Table 9), the low standardized loading is cause for question. Overall fit for this model is mediocre. The chi-square is 4626.357 , which does not indicate good fit. The CFI and NFI indicate mediocre fit, at .814 and .782 respectively. The RMSEA indicates good fit, at .067 with a $90 \%$ confidence interval ranging from .066 to .072 . All standardized and unstandardized loadings for this model are provided in Table 9.

The final step for this stage was the calculation of reliability statistics. For the Kindness scale, the alpha is .917. For the Trust By Association scale, the alpha is .867. For the Cigarettes and Alcohol scale, the alpha is .856. For the Bribes scale, the alpha is .870. For the Manipulation scale, the alpha is .648. Finally, for the Treat Like A Peer Scale, the alpha is .838. Overall, with the exception of the Manipulation scale, the scales show strong internal consistency reliability.

Stage 3: Gaining Cooperation. A six-factor solution was best for the 54 items included in the EFA of the Gaining Cooperation for sexual abuse stage-based MO scale. This solution explains $52.39 \%$ of the scale's variance. One item did not load strongly onto any factors, and was removed from further analyses. A Scree Plot for this analysis can be seen as Figure 5, and correlations between factors are presented in Table 4.

The first factor determined by the EFA of this stage-based scale is made up of 6 items that describe perpetrators using manipulative strategies to convince their 
victims to participate in abusive sexual activity. Therefore, the factor is named "Manipulation," and includes example items such as "say you will love them more if they do this with you," and "say you will make up things to tell on them." Interestingly, this scale is made up of both items from the "bribes" and "threats" section of the MOQ, which were combined in this study for the Cooperation stage. This implies that there is an overlap between the two formerly separated sections. Two items on this factor are also cross-loaded. The item, "say you will teach them something" also loads onto the "Desensitization" factor (.351), and the item "say you will make things up to tell on them" also loads onto the Violence factor (.342). However, both items load more strongly onto this factor, so they were kept on this scale. All items on this factor, as well as their loadings, can be seen on Table 10.

The second factor on the Gaining cooperation scale is made up of ten items that are all indicators of violent or coercive behavior. Therefore, this factor is titled "Violence," and includes items such as "use force to make them do sexual things," and "say you will hurt their mother." All of the items on this factor come from the Threats section of the MOQ. All items on this factor, as well as their loadings, are provided in Table 10.

The third factor is made up of seven items describing behaviors such as purchasing "sexual" clothing items such as bathing suits or underwear, taking nude images, or exposing victims to nude images. This scale is titled "Use Of Pornography," covering both exposure to and the making of pornography. It includes items such as "take pictures or videos of them with their clothes off," and 
"have them watch you do sexual things with adults." All of the items on this factor come from the Bribes and enticements section of the MOQ. All items on this factor, as well as their loadings, are presented in Table 10.

The fourth factor on the Gaining cooperation scale is made up of items that indicate that the offender will give something to the victim in exchange for their cooperation in abusive sexual activity. Therefore, this factor is named "Bribes," and includes items such as "give them money just after sexual abuse," and "say you will take them places." There is one cross-loaded item on this scale, "say you will spend more time with them." This item also loads onto the "Manipulation" factor (.313), but loads more strongly onto this factor (.467). All of the items on this factor come from the Bribes section of the MOQ. All items on this factor, as well as their loadings, are provided in Table 10.

The fifth factor on this scale is made up of 12 items that describe actions the perpetrator takes to desensitize the victim to sexual contact. For this reason, the factor is titled "Desensitization," and includes items such as "touch them nonsexually," and "get them curious about sex." Three items cross-load onto the "Manipulation" factor, which are "get them curious about sex" (.318); "say how special they are to be doing this with you" (.339); and "talk more and more about sex" (.335). All three load more strongly onto the Desensitization factor $(.483, .344$, and .343 , respectively). However, the closeness of these loadings indicates that the items, particularly the latter two, could be a good fit for either factor. The three items, however, remained on the Desensitization factor for this analysis. All of the 
items on this factor come from the Bribes section of the MOQ. All items on this factor, as well as their loadings, are provided in Table 10.

The final factor on this scale is made up of 8 items that describe ways in which perpetrators direct victims to engage in sexual activity with both the perpetrator and others. It also includes items regarding cigarettes and alcohol. This factor seems a bit disjointed, but the highest loadings indicate participation in sexual activity, so the factor is named "Directed Participation In Abusive Acts." Sample items include, "have them join in on sex between you and another child," and "have them do sexual things with other children." All of the items on this factor come from the Bribes section of the MOQ. All items on this factor, as well as their loadings, are provided in Table 10.

Next, a CFA was conducted replicating the structure found in the EFA for the Gaining cooperation scale. A model of the CFA can be seen in Figure 6. All six first order factors load strongly onto the second order factor, implying that these are all good indicators of gaining the cooperation of a victim. The standardized loadings are as follows: Manipulation loads at .899, Violence loads at .452, Use of pornography loads at .608, Bribes loads at .835, Desensitization loads at .809, and Participation at .522. However, the overall fit for this model is poor. The chi-square is 8578.32. The CFI and NFI both indicate poor fit, at .709 and .675 respectively. The RMSEA indicates decent fit, at .079 with a 90\% confidence interval ranging from .077-.08. All standardized and unstandardized loadings for this model can be found in Table 11. 
Finally, reliability statistics were calculated for each factor. For the Manipulation scale, the alpha is .775. For the Violence scale, the alpha is .852. For the Use of pornography scale, the alpha is .799. For the Bribes scale, the alpha is 907. For the Desensitization scale, the alpha is .906. Finally, the alpha for the Participation scale is .795. This indicates either good to very good internal consistency reliability, depending on the scales, with Bribes and Desensitization standing out as particularly good.

Stage 4: Sexual Abuse. A five-factor solution was best for the 26 items included in the EFA of the Sexual abuse stage-based scale. This solution explains $52.52 \%$ of the scale's variance. Two items did not load strongly onto any factors, and were removed from further analyses. A Scree Plot for this analysis is presented in Figure 7, and correlations between factors can be seen on Table 5.

The first factor on the Sexual abuse scale is made up of six items that describe actions that perpetrators have victims do to them. For this reason, the factor is titled "Self-serving Sexual Behavior," and includes items such as "masturbate you for awhile," and "touch your penis." One item on this factor, "rub them against you," is cross-loaded onto the "sexual touch" factor (.350). As it loads more strongly onto this factor (.474), it is included here. All items on this factor, as well as their loadings, can be seen on Table 12.

The second factor on this scale is made up of five items that indicate abuse of a female victim. The factor is therefore named "Abuse Of A Female Victim," and includes items such as "put your penis into their vagina," and "put your finger into 
their vagina." One item on this factor, "touch their breasts or nipples," cross-loads onto the sexual touch factor (.362), but is retained on the Abuse Of A Female Victim factor as it loads here more strongly (.401). All items on this factor, as well as their loadings, can be seen on Table 12 .

The third factor on the Sexual abuse scale is made up of two items that both describe the perpetrator anally penetrating the victim. As such, the factor is named "Anal Penetration." It includes the items "try to put your penis into their anus," and "put your penis into their anus." Both of these items and their loadings can be seen on Table 12.

The fourth factor on the Sexual abuse scale is made up of six items that describe non-penetrative sexual touch. It is therefore called "Sexual Touch," and includes items such as "rub them sexually with them knowing," and "touch their vagina or penis." All items on this factor, as well as their loadings, can be seen on Table 12.

The final factor on this scale is made up of five items that describe abusive acts related to buttocks, which include both the victim doing something to the buttocks of the perpetrator and the perpetrator doing something to the buttocks of the victim. For this reason, the factor is called "Buttock Related Abuse." Example items include "touch your buttocks," and "put their penis into your anus." All items on this factor, as well as their loadings, can be seen on Table 12.

Next, a CFA was conducted replicating the structure found in the EFA for the Gaining cooperation scale. A model of the CFA can be seen as Figure 8. All five first- 
order factors load strongly onto the second-order factor of sexual abuse. The standardized loadings are as follows: Self-Serving Behavior loads at .881, Abuse Of A Female Victim loads at .497, Anal Penetration loads at .580, Sexual Touch loads at .863, and Buttock Related Abuse loads at .713. The overall model fit is mediocre. The chi-square statistic is 8578.317. The CFI and NFI are both mediocre, at .829 and .805 respectively. The RMSEA is also mediocre, at .077 with a $90 \%$ confidence interval ranging from .073-.081. All standardized and unstandardized loadings for this model can be found on Table 13.

Finally, reliability statistics were calculated for each factor in the model. The alpha for Self-serving Abuse is .852. The alpha for Abuse Of A Female Victim is .764. The alpha for Anal Penetration is .854. The alpha for Sexual Touch is .753. Finally, the alpha of Buttock Related Abuse is .670. All reliability statistics indicate decent reliability, with the final factor, Buttock Related Abuse, being less reliable than the other scales.

Stage Five: Silencing. A two-factor solution was best for the 23 items included in the EFA of the Silencing stage-based scale. This solution explains $51.74 \%$ of the scale's variance. All items included loaded onto one of the two factors. The correlation between the two factors is .580. A Scree Plot for this analysis can be seen as Figure 9.

The first of the two factors that make up the Silencing stage is made up of 11 items that describe perpetrators threatening to remove benefits of positive aspects of the relationship if the victim tells anyone about the abuse, as well as bribes. As 
such, the factor is named "Bribes and Removal of Benefits," and example items include "say you cannot go places together if anyone knew," and "say you will give them privileges if they do not tell." All items on this factor, as well as their loadings, can be seen on Table 14 .

The second factor on the Silencing scale is made up of 12 items that describe more threatening behaviors that perpetrators use to silence their victims.

Therefore, the factor is named "Threats to Silence," and includes items such as "hurt them as a warning," and "hope they thought you would get them in trouble." All items on this factor, as well as their loadings, can be seen on Table 14 .

The CFA for this scale had a different structure, as a second order factor model needs at least three first order factors to be identifiable (Kline, 2011). So, though the CFA is a replica of what was found in the EFA, the two first order factors were correlated, instead of loaded onto a second-order factor. The correlation between these two factors is .726, which indicates that there is evidence for an underlying "Silencing" factor. The overall model fit is mediocre, with a chi-square of 2292.97. The CFI and NFI both indicate mediocre fit, at .821 and .806 respectively. The RMSEA indicates poor fit, at .101, with a 90\% confidence interval ranging from .097 to .104 . All standardized and unstandardized loadings for this model can be found on Table 15.

Finally, reliability statistics for both factors were calculated. The Bribes factor has an alpha of .923, and the Threats factor has an alpha of .859. This indicates that both factors are reliable. 
Analytic Conclusions. Overall, the analyses indicate that while it was useful to explore the factor structure of the MOQ, some work needs to be done to continue fine-tuning the measure for empirical use. It should be noted that the CFA process used in this analysis is merely fitting the data, and the fit for all five scales is well below standard goodness-of-fit recommendations. When the fit is good, it is through the RMSEA. However, the RMSEA is a better fit when models have more items, leading to more degrees of freedom. As the RMSEA is a per-degree of freedom fit index, meaning that it will have more power and be a better predictor for models with more degrees of freedom (Steiger \& Lind, 1980; MacCallum, 1998). The goodness of fit through the RMSEA should not be discounted, as MacCallum (1998) suggests that the RMSEA is one of the best fit indices to utilize, but it should be noted that other fit indices to not show good fit.

This shows that there are some issues with the underlying structure of the MOQ that need to be discovered and addressed, in order to have better stage-based scales that are a good theoretical fit for offender modus operandi. One finding that indicates that the process is moving in the right direction is that all but one of the first order factors loaded strongly onto their respective second order factor. This indicates that the structure has the right parts, even if it does need more adjustment. Reliability statistics for most of the factors were either good or excellent (ranging from .75-.99), which also shows that they have promising utility for empirical research. The next section will delve further into what potential issues led to poor model fit, and what can be done in the future to address these issues. 


\section{Chapter 9: Discussion}

The Modus Operandi Questionnaire (MOQ) reflects a complex measure that offers psychometric challenges beyond those typically encountered in test construction. While most measures assess a focused trait, behavior or personality factor, the MOQ seeks to examine a broad range of behaviors intended to achieve a variety of proximal aims with the ultimate goal of successfully completing child sexual abuse and avoiding detection. Further, with many dimensions that are assessed, there is a circumscribed nature to the components that comprise that focus (e.g., depression, anxiety, hyperactivity). In contrast, it is known that the modus operandi of child sexual abusers is heterogeneous and that perpetrators can utilize a broad range of behaviors to accomplish their abusive intent. Finally, as with many other psychological areas of measurement, the clinical assessment needs regarding the MOQ may be somewhat different than the research demands on the measure. Overall, this makes for a much more complex measurement development process, requiring a strategic balancing of assessment needs.

This chapter will begin with a focus on the MOQ as a research measure and further delve into the analyses described in the Results section for each stage-based MO scale. Specific suggestions for each dimension will be offered to improve the MOQ as a research tool. Discussion will provide attention to the ways in which a more psychometrically sound MOQ may contribute to the CSA literature. Consideration will also be given to the MOQ as a clinical measure and how study findings bolster its use with offenders as part of their treatment process. Finally, 
study limitations will be outlined, and future research directions to further enhance the MOQ will be described.

\section{Strengthening the MOQ as a Research Measure}

Accessing. The five factors found to represent accessing victims in this study are Relationship Building, Caretaking, Violence, Going Places, and Cigarettes and Alcohol. Of note is that none of these factors are correlated above .363, indicating that they represent distinct MO strategy groups that offenders utilize to groom their victims. Further, as all five factors load strongly onto the second-order Accessing factor in the CFA Model, they can be interpreted as strong indicators of the MO Accessing stage. Another interesting note is that the Violence factor is negatively correlated with all other factors, indicating that offenders who use violence to access their victims are different than those who rely on other strategies.

The Accessing MO stage has the least variance explained by the EFA of the five stage-based scales, and the CFA model fit was not good. This is likely due to the possibility that offenders' methods for accessing their victims may have more to do with situational circumstances than particular behavioral choices made by the offender. For example, CSA offenders who live with their victim, or have a caretaking role (e.g., baby-sitting) will have a much easier time utilizing care-taking strategies to set up their victim's abuse than an organizational offender (e.g., a teacher) or an offender who finds their victim at a local park. Further, as this is the first time any work has been done with the factor structure of the accessing stage of the MOQ, there may need to be more fine-tuning to better determine both the 
wording of specific items on the scale, and the selection of the best possible items to assess this dimension. Overall, this analysis found strong evidence for five different groupings of MO strategies that define the accessing stage, which can be fine-tuned and further explored in the future to determine a better theoretical model underlying this MO stage.

Gaining Trust. The Gaining trust model is one of the two with the best fit, of the five measured, with five first-order factors that loaded strongly onto the second order factor. Of interest in this model is the fact that one of the six factors found in the exploratory analysis, Cigarettes And Alcohol, did not load strongly onto the second-order factor of Gaining trust in the Confirmatory model. This implies that utilizing cigarettes and alcohol may not be a way to gain the trust of a victim, and these items may need to be reconsidered within this stage.

Another point of interest in the Gaining trust stage is the strong but negative loadings on the Bribes factor in the EFA. While the negative loadings could be due to the oblique rotation (Tabachnik \& Fidell, 2001), the Bribes factor is also negatively correlated with all of the other factors (see Table 3). It is possible that this is because bribing a victim to gain their trust differs from the more relational strategies that define the other factors. The exception to this is, however, is Cigarettes And Alcohol, which has been determined to be a poor indicator of gaining trust. Bribes on the MOQ are generally material in nature, such as giving the victim toys, money, or other gifts. Other individuals, such as the parents of the victim, may notice their child coming home with toys, candy, or other gifts. This implies that the 
offender would need to have a strong relationship with the family of the victim, or would need to have a great deal of power with the family for such gifts not seem out of the ordinary. It follows that those offenders who are involved in a situation where they are able to gain the trust of their victim through giving gifts and bribery may be a different type of offender than those perpetrators who use more relational tactics. If this is the case, it could also explain the negative correlations found between using bribes and using other MO strategies.

Finally, it is worth comparing the factor structure found in this study to the structure found in the 1997 study (Kaufman et al., 1997). Three factors were found in the 1997 study for this MO stage: (1) Drugs And Alcohol; (2) Love, Attention, And Gifts; and (3) Trust By Association. Interestingly, in the current study, all items related to drugs were dropped from the analyses due to their low endorsement (Table 1). However, the Drugs And Alcohol factor in the 1997 study is a mirror image of the Cigarettes And Alcohol factor in this study. Trust By Association shows up in both analyses, and the Love, Attention, and Gifts factor (22 items in the 1997 study) seems like it could have been a catch-all category for the remaining items. The new factor solution, which includes the factors Bribes, Kindness, Treat Like A Peer, and Manipulation, delves further into the nuances of the strategies offenders use to gain the trust of their victim and appears to be an improvement over the initial factor structure. Further, the 1997 analysis of the Gaining Trust stage only explained $41.58 \%$ of the variance, whereas this new analysis explains $53.43 \%$-- an almost $12 \%$ increase. This demonstrates that the updated factor structure allows 
for greater sensitivity to the nuances associated with these MO behaviors, while also explaining a greater proportion of the variance.

Study findings suggest that additional consideration should be given to the Bribes factor and the Cigarettes And Alcohol factor. It may be necessary to remove the cigarettes and alcohol items from the scale, as they do not seem to be predictors of this MO stage. It is also worth considering future empirical studies that examine how offenders who use bribes to gain the trust of their victims might differ from other offenders who do not use this type of strategy.

Gaining Cooperation. While the overall fit of the Gaining cooperation model was the poorest of the five, all six factors found in the EFA were shown to be strong predictors of the second-order factor, Gaining Cooperation, in the CFA. This means that while work needs to be done to strengthen the measure, the factors found, Bribes, Violence, Desensitization, Participation, Manipulation, and Use Of Pornography, are all types of strategies that offenders appear to use in order to gain the cooperation of their victims.

This stage differed from past analyses in that the Bribes And Threats For Cooperation sections of the MOQ were combined into a single Cooperation stage (i.e., whereas they had been analyzed separately in the past). Of note is the fact that in this study, many of the threat items were dropped from analyses due to very low endorsement rates (Table 1). The threat items that remained in the analyses loaded onto either the Violence factor or the Manipulation factor. The Violence factor is made up of all threat items, and the Manipulation factor is made up of a combination 
of bribe items as well as threat items. This may warrant future investigations into differences between offenders who use threats to gain cooperation, and those who do not. It is possible that perpetrators who are overtly violent may utilize MO differently than those who are less violent in their offending.

Also of interest, the Gaining Cooperation items that have to do with cigarettes and alcohol loaded onto the Directed Participation In Abusive Act factor, and yet, they do not seem to align with the other items on this scale. This combined with lower loadings for Cigarettes And Alcohol onto the Access (.388) and Gaining Trust (.195) scales, may warrant further investigation into offenders who use drugs, cigarettes, and alcohol as part of their MO process. These findings may reflect a quantitatively different group of offenders. On the other hand, these findings may suggest that victim age is a factor in here. More specifically, offenders typically utilize these strategies with older victims and much less so with younger victims. Clearly, there is a need for additional investigations to more carefully examine the specific role of cigarettes and alcohol as part of the CSA MO process.

In general, more work needs to be done to strengthen this section of the MOQ. Additional investigations should explore possible group differences between offenders who use threats, and those who do not. There should also be a more careful examination of this section at the item level to help strengthen the scale and to enhance the utility of this section of the MOQ. Studies in both these areas may offer directions to increase the overall fit for the Gaining Cooperation section of the MOQ. 
Sexual Abuse. This study also marks the first time that the sexual abuse section of the MOQ has been factor analyzed, and as such, it is notable that the factor structure is as "clean" as it is. The scale broke down into five factors that all strongly loaded onto the second-order factor of sexual abuse in the CFA model. At the same time, however, the model fit was mediocre on all accounts. Of note is that SelfServing Abuse and Sexual Touch are moderately correlated, at .570 (Table 5). This indicates that the two strategies may often be used together by offenders.

Another interesting aspect of this analysis is that factors may have separated based on the gender of the victim. Namely, the Abuse Of A Female Victim factor contains all of the items that are concerned with touching or penetrating a vagina. While both male and female victims could be subjected to anal penetration, it is interesting that the items having to do with penetrating an anus with a penis loaded onto a factor separate from the one in which other buttock-related items loaded. It would be interesting, in the future, to look at these items and factors based on the preferred victim gender of the perpetrators. Findings may help clarify the meaning of these items' differential factor loadings. Overall, this analysis was a good start for further developing the sexual abuse stage of the MOQ. As noted, more work could be done to look at effects of victim gender, which may enhance overall model fit.

Silencing Victims Following Abuse Onset. The analyses for the Silencing scale closely replicated the results of the EFA conducted in the 1997 study (Kaufman et al., 1997). Though one of only two stage-based scales that were analyzed in the same way, both iterations of the analysis broke down into Bribes and Threats. Of 
note is that this version of the analysis removed many of the more overtly violent threat-based items, due to low endorsement rates (Table 1). For this reason, it is interesting to note that the remaining items still separated into basically the same two scales. That said, however, the relatively high correlation between the two factors (.580), suggests that bribes and threats may be used simultaneously by a good proportion of offenders.

The overall fit for the Silencing CFA model is also mediocre, and the model for this stage was limited by the presence of only two factors which is problematic, since a second-order CFA needs at least three first-order factors to be identified (Kilne, 2011). Still, the factors are correlated at .726 in the CFA model, which implies that there may be support for a second-order factor model. (i.e., if another factor were present, so that this could be empirically tested).

Overall, it is evident that offenders use both bribes and threats to maintain the silence of their victims after abuse. Future studies should examine differences related to when bribes and threats are employed and the extent to which the use of these two different strategies is mediated by contextual factors associated with the abuse.

\section{Group Differences and The MOQ as a Research Measure.}

The most significant issue with the results of this study is the poor model fit for all five CFAs tested. This study was conceptualized as an examination of the structure of the MOQ across all types of CSA offenders. However, the findings of this study suggest that group differences may be at the root of the poor model fit for all 
five MO stages subjected to a CFA. A potential solution to this problem would be to have different versions of the MOQ based on factor analysis of key offender subgroups (e.g., adult offenders, juvenile offenders, offenders of female victims, offenders of male victims). The existing literature reflects knowledge of such group differences (Kaufman et al., 1995; 1998), which adds to the case for these differences greatly limiting CFA model fit.

It is also important to consider that having multiple versions of the MOQ based on group differences may greatly limit the ability to directly compare subgroups, making it more difficult to enhance knowledge about group differences on various dimensions. For example, if different factor structures are identified for various offender subgroups (e.g., adult vs. adolescent offenders), resulting in different MOQ forms, then the measure would no longer lend itself to comparisons across these groups.

The literature suggests that there is no one sex offender "profile," which means that the variance being explained by individual differences will be quite difficult to measure. However, looking at structural group differences may offer some benefits for improving the MOQ. Rational Choice Theory (Cornish \& Clarke, 1986) posits that offenders make offending choices in part by examining the situational variables around them in order to determine which strategies will help them successfully offend while avoiding detection. A look at the items on the MOQ shows that certain represented MO strategies would be impossible for a certain type of offender to carry out without detection. For example, consider the "Caretaking" 
factor on the Access scale. This factor includes items such as "have sole custody," and "take a bath/shower with them." These strategies would be quite easy for an intra-familial offender (e.g., father), or potentially a baby-sitter, to utilize. It would be much more difficult for an extra-familial offender, such as a doctor or teacher, to employ. Further, as Access is part of that stage where offenders establish the abusive relationship, characteristics of the victim and the perpetrator are least likely to affect the particular strategies employed. For this reason, it seems logical to conclude that the minimal variance accounted for by the MO Access area may be due in large part to this mismatch of items and subgroups. It will be important to explore strategies to better account for group differences related to Access in future scale development work with the MOQ.

\section{Other Variables to Augment the MOQ}

Consideration should also be given to other types of variables that may account for the variance not currently accounted for by this version of the MOQ. As noted earlier, these studies may further examine other important variables that may need to be incorporated into any study of CSA offenders (e.g., situational variables, differential offender roles [e.g., babysitter, family friend, camp counselor]). In some cases, items may be directly added to the MOQ (e.g., a more detailed list of offender

roles). In other instances, it may be a matter of recommending the use of the MOQ in concert with measures or processes that account for other important dimensions (e.g., the Situational Prevention Approach in an organizational setting) and in this way, will increase variance accounted for by virtue of a battery of measures. 


\section{Future MOQ Confirmatory Factor Analyses}

This study conducted both EFAs and CFAs on the same pool of study participants in keeping with the recommendations of a paper by Van Prooijen and Van Der Kloot (2001). While this particular study provided support for the use of this approach, it is important to note that common practice is not to do EFAs and CFAs on the same participant group. Instead, it is typical to conduct the EFAs with one participant group and then complete the CFAs on a separate, non-overlapping cross-validation sample. For this reason, the CFA conducted in this study is not truly theory driven, but rather a mechanism to explore the structural fit of the current data. In future studies, Confirmatory work should be conducted on new samples of offenders to further examine the theoretical fit of the proposed MOQ EFA structure. Replications of this nature will help determine if consideration should ultimately be given to creating separate versions of the MOQ based on key offender subgroups as proposed above.

\section{Future Directions as a Research Tool}

This new psychometric analysis has provided the field with a better idea of how the MOQ can be better utilized in empirical research. The methodology of conducting an EFA and a CFA on the same data shows that more work needs to be done to enhance the model fit of the five stage-based factors, perhaps utilizing different questionnaires for different groups, or implementing other types of data reduction strategies. Enhancing the fit of the data will provide a measure that is reliable and valid for empirical use. The factors found in this analysis, across all five 
MO stages, can be utilized in studies that examine the relationship between MO and other contextual variables (e.g., where an offense took place, psychological characteristics of the offender). To improve the overall fit of the data, methodological studies can be conducted to further explore various MOQ measure properties.

For example, future studies on the MOQ could delve into Item Response Theory (IRT), as a means to analyze the scale at an item level. This would be useful in that it would better develop the psychometric characteristics of the MOQ, strengthening the overall measure. Studies could also examine relationships between scales reflecting the MO temporal stages, examining if high levels of a specific tactic in one stage predict high levels of a similar or related tactic in succeeding stages. For example, future studies may examine whether the use of a high frequency of threats in the gaining cooperation stage predicts the use of a high frequency of threats in the victim silencing stage. It could also be useful to see if specific MO strategies predict how violent the act of sexual abuse will be across temporal stages. Finally, cluster analysis work could be conducted to see if there are identifiable offender profiles across the MO process. This may have particular implications for planning offender treatment or placing offenders into groups containing perpetrators with similar issues to foster a more intensive focus on issues relevant to all group members.

An up to date factor analysis of the MOQ is a valuable contribution to the work done on situational factors that influence offending, as well as situational 
prevention. Differences in MO could be analyzed in conjunction with reported situational variables that made the abuse easier or more difficult to understand the full crime commission process, as suggested by Leclerc, Proulx, \& Beauregard (2009). The MOQ could also be adapted, as necessary, to best fit the process of different types of offenders, such as organizational offenders, or offenders who use the internet to access their victims. This would align with work that is being done in these areas on MO, such as internet offending (Elliott \& Beech, 2009; Kloess et al., 2015). There could also be more work done on how different groups of offenders utilize MO strategies, for example, intra- and extra-familial offenders.

\section{The MOQ as a Clinical Tool}

The MOQ has long been utilized as a clinical tool for sexual offender treatment providers to assess perpetrators' modus operandi and to contribute to the development of their individualized treatment plan (i.e., since the mid-1990s). Workshops have been provided around the country by MOQ creator, Dr. Kaufman, to train treatment providers on the clinical use of the MOQ (Kaufman \& Daleiden, 1995; Kaufman, Hilliker, \& Daleiden, 1995; Kaufman \& Uncapher, 1995; Kaufman, Daleiden, Hilliker, \& Wallace, 1995). In this capacity, the MOQ was intended both to identify the breadth of MO strategies previously used by a particular offender as well as to summarize the types of MO approaches that characterize an offender's perpetration. The heterogeneity of sex offending requires that the MOQ reflect the breadth of possible MO behaviors. The fact that the MOQ represents a measure that broadly samples the domain of MO behaviors lends itself to its use in identifying 
previously used patterns of behaviors that can be used in treatment planning that utilizes relapse prevention approaches (Marques et al., 2005) and/or the development of safety plans (Veneziano, Veneziano, \& LeGrand; 2000; e.g., to increase safety when returning juvenile sex offenders to their home and community). In both cases, a knowledge of early steps in a particular perpetrator's past offending process can help identify observable "red flags" reflecting movement toward re-offense that can be shared with parents, family members, probation/parole officers, and other guardians to increase safety and minimize the chances of reoffending (i.e., relapse). This underscores the importance of maintaining the MOQ to reflect the breadth of MO items (i.e., including low base-rate behaviors such as use of violence) for clinical purposes.

At the same time, the MOQ's clinical utility also relies on the ability to identify salient patterns that characterize an offenders' modus operandi and suggests the need for particular clinical treatment directions. For example, an offender's reliance on more threatening or violent MO strategies may reflect their need for anger management training or therapy to address the role of violence in their sexual arousal. Alternatively, a reliance on bribes and enticements to access younger victims may reflect a need to develop better peer appropriate social and dating skills. With this in mind, factor analytic based MOQ subscales can offer a clinician the ability to quickly identify areas of concern.

For this reason, the most useful aspect of this study for clinicians is likely the initial EFA. While there is clearly more to do to resolve the theory driven 
conceptualization of the MOQ, the EFAs reflect a strong data-driven factor structure for the MOQ. Moreover, this factor structure is largely consistent with a previous EFA of the MOQ with a different participant pool (Kaufman et al., 1997) and also boasts scales with strong internal consistency reliability (i.e., based on this study's findings). As such, findings from this study provide additional support for the continued use of the MOQ as a clinical measure for identifying factor based patterns of offenders' modus operandi. It may be beneficial for future studies to examine the extent to which the MOQ is found to be helpful by clinicians and the specific ways in which MOQ scales are useful in suggesting particular treatment needs.

\section{Limitations}

This study is not without its limitations. First, as a secondary data analysis process, there was no control over the way in which the data was collected. Further, the MOQ has limitations with regard to its self-report, retrospective nature. Even though anonymity has been assured, the sensitive nature of the MOQ items may lead to biased self-report. This could have particular relevance for any crime related information that has not been reported to the justice system. In fact, Kaufman and his colleagues found a propensity for juvenile sexual offenders to under-report more violent MO behaviors (Kaufman et al., 1993). At the same time however, research on offenders concludes that they generally respond truthfully to MO questions and are not subject to social desirability. This may be due, in part, to the large amount of time they spend talking about their past abusive behaviors as a part of their treatment. The MOQ items also ask participants to recall an offense that may have 
happened quite a few years ago. As a result, they may have difficulties accurately recalling particular aspects of their MO behaviors. However, since offending behaviors are typically a focus of their treatment, there is reason to believe that their salient nature and clinical focus on such behaviors in treatment may make this less of a concern.

Another limitation of the study is related to the type of sample collected. The MOQ in this study was only administered to convicted sex offenders. This means that only the perspectives of offenders who were identified, apprehended, and convicted or adjudicated for an offense are included, and the results may only be generalizable to that population. This may mean that the resulting factor structure may not be appropriate for use with non-convicted offenders, who may use very different MO tactics than convicted or adjudicated offenders. Given the challenges associated with collecting data from non-identified (i.e., non-convicted or adjudicated) offenders it is difficult to know if or in what ways their MOQ data may differ from the current study sample.

The length of the MOQ may also represent a study limitation. At 339 items, the MOQ takes a fair amount of time to complete, and original study participants also completed a number of other measures at the same time. This may have led to fatigue, which could have been a factor impacting how participants completed the MOQ. However, even though the measure was long, participants were given a break during the data collection and a snack halfway through the process. 
Another limitation related to the length of the survey is the low-base rates of nearly all items. The positive skew of the data was discussed in the previous chapter, and it is of note that only 46 of the 339 items on the MOQ have a mean above 1 , on a $0-3$ Likert scale. Theoretically and practically, this pattern of responding makes sense. As a clinical questionnaire, it is important that the MOQ is comprehensive, reflecting the full range of MO behaviors that an offender may employ. Further, since many offenders were only reporting on the perpetration of a single incident of sexual abuse, they may have had limited opportunities to utilize more than a handful of MO behaviors. At the same time, in considering the MOQ as a research tool, it may make sense, in the future, to utilize a data reduction strategy, such as a Principle Components Analysis, to determine which items may not be necessary for answering empirical questions. Another consideration would be to present all items on the MOQ more simply as dichotomous variables, to determine whether or not an offender engaged in a specific strategy, as opposed to how often they engaged in that particular strategy.

\section{Conclusion}

This study represents a new look at the structure of the Modus Operandi Questionnaire. For the first time, the questionnaire was broken up into five stagebased scales, based on the temporal model of MO. This included two sections that had never been formally factor analyzed, Accessing the victim, and the Sexual abuse. This analysis also combined Bribes for cooperation and Threats for cooperation into one stage-based scale, Cooperation. Overall, Exploratory Factor analyses found 
factor solutions that explained over half of the sample variance in all but one case (the Access scale), as well as a solution with limited cross loadings.

Secondly, this study utilized Structural Equation Modeling (SEM), through a CFA technique, to fit the MOQ data for this sample to examine how the first-order factors uncovered in the EFA related to stage-based second order factors, as well as to examine the overall fit of the proposed models. While fit for all five of the stagebased model can be improved, all but one of the first order factors were good indicators of their assigned second order factor, and most were shown to have good or excellent reliability. For this reason, the factors found in this study can be reintroduced to the field, as a means to add more specificity to the types of MO strategies examined in empirical research.

The MOQ also has strong utility in the clinical realm, and the updated factor structure can help clinicians to better understand the offenders that they work with, in order to help prevent recidivism. Finally, the utility of the MOQ in both the research and the clinical realm will help to inform prevention programming, potentially assisting in the eventual eradication of child sexual abuse. 
Table 1.

Low Endorsement MOQ Items

\begin{tabular}{|c|c|c|}
\hline Item & Stage-based Scale & $\begin{array}{l}\text { "Never" } \\
\text { Percentage }\end{array}$ \\
\hline Give them drugs & Access & 95.3 \\
\hline Tell them you'd hurt their friend if they didn't go & Access & 95.7 \\
\hline Tell them you'd hurt their pet if they didn't go & Access & 96.6 \\
\hline Let them see you had a weapon & Access & 95.3 \\
\hline Hurt their pet & Access & 97.5 \\
\hline Hurt some other animal & Access & 97.8 \\
\hline Hurt a member of their family & Access & 95.4 \\
\hline Threaten them with a weapon & Access & 96.1 \\
\hline Give them drugs & Gaining Trust & 95.9 \\
\hline Give them drugs just after sexual abuse & Gaining Cooperation & 95.6 \\
\hline $\begin{array}{l}\text { Show them pictures or videos of you having sex } \\
\text { with other adults }\end{array}$ & Gaining Cooperation & 95.4 \\
\hline $\begin{array}{l}\text { Have them watch children do sexual things with } \\
\text { each other }\end{array}$ & Gaining Cooperation & 95.3 \\
\hline $\begin{array}{l}\text { Show them pictures or videos of you having sex } \\
\text { with kids }\end{array}$ & Gaining Cooperation & 97.9 \\
\hline $\begin{array}{l}\text { Have them join in sex between you and another } \\
\text { adult }\end{array}$ & Gaining Cooperation & 96.3 \\
\hline $\begin{array}{l}\text { Have them take pictures or videos of you doing } \\
\text { sexual things with kids }\end{array}$ & Gaining Cooperation & 98.4 \\
\hline Have them take pictures or videos of you having sex & Gaining Cooperation & 98.1 \\
\hline $\begin{array}{l}\text { Show them media with adults doing sexual things } \\
\text { with kids }\end{array}$ & Gaining Cooperation & 96.6 \\
\hline Show them media with naked children & Gaining Cooperation & 95.7 \\
\hline $\begin{array}{l}\text { Show them media with kids doing sexual things } \\
\text { together }\end{array}$ & Gaining Cooperation & 96.2 \\
\hline Show them media with animals doing sexual things & Gaining Cooperation & 97.9 \\
\hline $\begin{array}{l}\text { Show them media of people doing sexual things } \\
\text { with animals }\end{array}$ & Gaining Cooperation & 98.5 \\
\hline Put a weapon where they could see it & Gaining Cooperation & 95.4 \\
\hline Tell them you had a weapon & Gaining Cooperation & 96.1 \\
\hline Say you will tie them up & Gaining Cooperation & 96.4 \\
\hline Say you will hurt them with a gun & Gaining Cooperation & 97.9 \\
\hline Say you will hurt them with a knife & Gaining Cooperation & 96.5 \\
\hline Say you will hurt them with another object & Gaining Cooperation & 97.9 \\
\hline Say you will hurt their father & Gaining Cooperation & 97 \\
\hline Say you will hurt their friends or relatives & Gaining Cooperation & 97.1 \\
\hline Say you will hurt their pet & Gaining Cooperation & 97.1 \\
\hline Say you will kill them & Gaining Cooperation & 95.2 \\
\hline Say you will kill their sibling & Gaining Cooperation & 97.2 \\
\hline Say you will kill their mother & Gaining Cooperation & 96.9 \\
\hline Say you will kill their father & Gaining Cooperation & 97.3 \\
\hline Say you will kill their friends or relatives & Gaining Cooperation & 97.5 \\
\hline Say you will kill their pet & Gaining Cooperation & 97.1 \\
\hline Get them drunk & Gaining Cooperation & 95.2 \\
\hline
\end{tabular}


Low Endorsement MOQ Items

\begin{tabular}{lll}
\hline Item & Stage-based Scale & "Never" \\
& & Percentage \\
\hline Get them high with drugs & Gaining Cooperation & 96.5 \\
Get them high with prescription drugs & Gaining Cooperation & 97.5 \\
Tie them up & Gaining Cooperation & 96.7 \\
Hurt a pet in front of them & Gaining Cooperation & 98 \\
Hurt their friends & Gaining Cooperation & 98.1 \\
Hurt a family member in front of them & Gaining Cooperation & 97.3 \\
Urinate or defecate on them & Sexual Abuse & 98 \\
Have them urinate or defecate on you & Sexual Abuse & 98.9 \\
Have them hurt you as part of sexual acts & Sexual Abuse & 98.6 \\
Say you would tie them up & Silencing & 96.7 \\
Say you would hurt them with a gun & Silencing & 97.1 \\
Say you would hurt them with a knife & Silencing & 96.7 \\
Say you would hurt them with another object & Silencing & 97.4 \\
Say you would hurt their siblings & Silencing & 96.2 \\
Say you would hurt their mother & Silencing & 95.5 \\
Say you would hurt their father & Silencing & 96.6 \\
Say you would hurt their friends or relatives & Silencing & 97.1 \\
Say you would hurt their pet & Silencing & 97.7 \\
Say you would kill their siblings & Silencing & 97.5 \\
Say you would kill their mother & Silencing & 97.1 \\
Say you would kill their father & Silencing & 97.7 \\
Say you would kill their friends or relatives & Silencing & 98.2 \\
Say you would kill their pet & Silencing & 98.1 \\
Hurt a friend in front of them as a warning & Silencing & 98 \\
\hline & & \\
\hline
\end{tabular}




\section{Table 2.}

\begin{tabular}{lrrrrr}
\multicolumn{6}{c}{ Access Factor Correlations } \\
\hline 1 & 1 & 2 & 3 & 4 & \multicolumn{1}{l}{5} \\
\hline 1. & - & & & & \\
2 & -.322 & - & & & \\
3 & .314 & -.238 & - & & \\
4 & .299 & -.078 & .363 & - & \\
5 & .227 & -.140 & .320 & .212 & - \\
\hline
\end{tabular}

Note. 1. Relationship Building; 2. Violence; 3. Going Places;

4. Caretaking; 5. Cigarettes and alcohol 


\section{Table 3.}

Trust Factor Correlations

\begin{tabular}{lrrrrrr}
\hline & 1 & 2 & 3 & 4 & 5 & 6 \\
\hline 1 & - & & & & & \\
2 & .267 & - & & & & \\
3 & .109 & .255 & - & & & \\
4 & -.455 & -.431 & -.189 & - & & \\
5 & .217 & .269 & .152 & -.091 & .164 & - \\
6 & .494 & .366 & .267 & -.442 & .164
\end{tabular}

Note. 1. Kindness; 2. Trust by Association; 3. Cigarettes and Alcohol; 4. Bribes; 5. Manipulation; 6. Treat like a Peer 
Table 4.

Cooperation Factor Correlations

\begin{tabular}{lrrrrrr}
\hline Factor & 1 & 2 & 3 & 4 & 5 & 6 \\
\hline 1 & - & & & & & \\
2 & .211 & - & & & & \\
3 & .175 & .206 & - & & & \\
4 & .247 & .214 & .333 & - &. & \\
5 & .325 & .056 & .254 & .452 & .171 & - \\
6 & .270 & .340 & .406 & .189 & .179
\end{tabular}

Note. 1. Manipulation; 2. Violence; 3. Use of Pornography; 4. Bribes; 5.

Desensitization; 6. Participation 
Table 5 .

Sexual Abuse Factor Correlations

\begin{tabular}{lrrrrr}
\hline Factor & 1 & 2 & 3 & 4 & 5 \\
\hline 1 & - & & & & \\
2 & .276 & - & & & \\
3 & .234 & .140 & - & & \\
4 & .570 & .342 & .115 & - & - \\
5 & .388 & .173 & .308 & .249 & - \\
\hline
\end{tabular}

Note. 1. Self-serving Abuse; 2. Abuse of a Female; 3. Anal Penetration; 4. Sexual Touch; 5. Buttock Related Abuse 
Table 6.

Accessing Exploratory Factor Loadings

\begin{tabular}{|c|c|c|c|c|c|}
\hline & 1 & 2 & 3 & 4 & 5 \\
\hline tell them you will do something fun & .692 & .065 & .021 & .027 & .018 \\
\hline $\begin{array}{l}\text { threaten with ending of privileges } \\
\text { or rewards }\end{array}$ & .625 & -.179 & -.110 & .038 & .044 \\
\hline $\begin{array}{l}\text { telling them they'd get special } \\
\text { rewards or privileges }\end{array}$ & .617 & -.001 & -.091 & .088 & .068 \\
\hline give them toys or candy & .595 & -.013 & -.022 & .110 & .037 \\
\hline tell them you can be trusted & .576 & .014 & .093 & .083 & -.039 \\
\hline $\begin{array}{l}\text { tell the you won't spend time with } \\
\text { them if they didn't go }\end{array}$ & .560 & -.197 & .035 & -.072 & .038 \\
\hline $\begin{array}{l}\text { tell them you are older and they } \\
\text { should do what you say }\end{array}$ & .560 & -.244 & .108 & .009 & -.105 \\
\hline $\begin{array}{l}\text { tell them they would get in trouble } \\
\text { if they didn't go }\end{array}$ & .555 & -.330 & .072 & -.097 & -.022 \\
\hline defend them from bullies & .455 & .031 & .083 & .193 & .092 \\
\hline $\begin{array}{l}\text { tell them you would get in trouble } \\
\text { if they didn't go }\end{array}$ & .453 & -.287 & .061 & -.068 & -.007 \\
\hline give them money & .384 & -.012 & -.063 & .226 & .241 \\
\hline $\begin{array}{l}\text { tell them parents said to go with } \\
\text { you }\end{array}$ & .340 & -.180 & .197 & -.009 & .001 \\
\hline watch t.v. with them & .330 & .101 & .185 & .300 & -.063 \\
\hline $\begin{array}{l}\text { pretend to be someone they like or } \\
\text { trust }\end{array}$ & .329 & -.110 & .187 & -.134 & -.007 \\
\hline $\begin{array}{l}\text { being at home of friend or relative } \\
\text { with permission }\end{array}$ & .152 & -.003 & .083 & .084 & .126 \\
\hline $\begin{array}{l}\text { tell them you would hurt them if } \\
\text { they didn't go }\end{array}$ & .051 & -.747 & .002 & -.043 & .104 \\
\hline hurt them & -.026 & -.738 & .036 & .004 & .037 \\
\hline use physical force to make them go & -.004 & -.730 & .009 & -.079 & .026 \\
\hline get angry or violent with them & .089 & -.667 & .098 & .044 & -.090 \\
\hline $\begin{array}{l}\text { tell them you had hurt others or } \\
\text { had a bad temper }\end{array}$ & 165 & -.616 & -.121 & .145 & -.047 \\
\hline $\begin{array}{l}\text { tell them you'd hurt their family if } \\
\text { they didn't go }\end{array}$ & -.040 & -.532 & .081 & -.032 & .245 \\
\hline $\begin{array}{l}\text { hoping they thought you'd hurt } \\
\text { them if they didn't go }\end{array}$ & .199 & -.481 & -.098 & .081 & .034 \\
\hline $\begin{array}{l}\text { let them see you angry or violent } \\
\text { with another person }\end{array}$ & .253 & -.442 & .011 & .178 & -.068 \\
\hline take them to parks & .078 & .005 & .797 & -.082 & -.066 \\
\hline go to playground & .076 & -.065 & .745 & -.091 & -.133 \\
\hline go to shopping mall & -.098 & -.030 & .744 & -.005 & -.026 \\
\hline take them to the movies & -.008 & .034 & .655 & .033 & .051 \\
\hline take them to school & -.065 & -.025 & .641 & .126 & -.081 \\
\hline take them to the video arcade & .006 & -.086 & .561 & -.015 & .081 \\
\hline take them camping & -.028 & -.011 & .510 & .091 & .088 \\
\hline go for car ride with them & .056 & 107 & .454 & .197 & .112 \\
\hline be together for a holiday & .177 & .034 & .373 & .295 & -.050 \\
\hline
\end{tabular}


Accessing Exploratory Factor Loadings

\begin{tabular}{|c|c|c|c|c|c|}
\hline & 1 & 2 & 3 & 4 & 5 \\
\hline go swimming with them & .105 & .049 & .360 & .221 & .160 \\
\hline take them on overnight trips alone & -.034 & .020 & .330 & .164 & .223 \\
\hline $\begin{array}{l}\text { take them places during the day } \\
\text { alone }\end{array}$ & .149 & .126 & .329 & .147 & .216 \\
\hline $\begin{array}{l}\text { go to isolated or out of the way } \\
\text { place }\end{array}$ & .097 & -.083 & .281 & -.099 & .251 \\
\hline $\begin{array}{l}\text { letting them see you with other } \\
\text { children }\end{array}$ & .213 & .085 & .274 & .060 & .071 \\
\hline having a pet to show and play with & .195 & -.118 & .230 & -.095 & .123 \\
\hline tuck them in bed & .094 & .001 & .080 & .669 & -.050 \\
\hline give them a bath & .011 & -.107 & .049 & .572 & .015 \\
\hline take a bath/shower with them & -.019 & -.059 & .019 & .519 & .106 \\
\hline being at home with permission & .021 & .085 & -.012 & .502 & .010 \\
\hline $\begin{array}{l}\text { being home alone due to time } \\
\text { difference with parent or spouse }\end{array}$ & .014 & .046 & -.081 & .498 & -.013 \\
\hline let them sleep in my bed & .049 & .050 & .139 & .492 & .059 \\
\hline sneak into their bedroom at night & .109 & -.045 & -.005 & .478 & .025 \\
\hline baby-sit & .221 & .065 & -.068 & .455 & -.049 \\
\hline have sole custody & -.125 & -.173 & .056 & .348 & -.072 \\
\hline $\begin{array}{l}\text { let them stay up after parent had } \\
\text { gone to bed }\end{array}$ & .298 & .041 & .072 & .316 & .139 \\
\hline $\begin{array}{l}\text { have them baby-sit for own } \\
\text { children }\end{array}$ & -.013 & -.030 & .055 & .268 & .039 \\
\hline take them out of school & -.157 & -.201 & .207 & .242 & .094 \\
\hline $\begin{array}{l}\text { see them on weekend visit (if } \\
\text { divorced or separated) }\end{array}$ & .010 & -.012 & .101 & .175 & .035 \\
\hline give them cigarettes & .034 & .024 & -.046 & -.067 & .683 \\
\hline give them alcohol & -.065 & -.106 & -.047 & .025 & .618 \\
\hline
\end{tabular}

Note. 1. Relationship Building; 2. Violence; 3. Going Places; 4. Caretaking; 5. Cigarettes and Alcohol. All loadings above .3 are bolded 
Table 7.

Accessing Model Path Estimates

\begin{tabular}{|c|c|c|c|}
\hline Item & Factor & $\begin{array}{r}\text { Standardized } \\
\text { Estimates } \\
\end{array}$ & $\begin{array}{r}\text { Unstandardized } \\
\text { Estimates } \\
\end{array}$ \\
\hline Relationship Building & Access & .816 & .638 \\
\hline Cigarettes/Alcohol & Access & .388 & .117 \\
\hline Violence & Access & .557 & .235 \\
\hline Caretaking & Access & .648 & .338 \\
\hline Going Places & Access & .673 & .343 \\
\hline 60 & Relationship Building & .639 & 1.000 \\
\hline 66 & Relationship Building & .678 & .899 \\
\hline 51 & Relationship Building & .562 & 1.118 \\
\hline 52 & Relationship Building & .620 & .958 \\
\hline 59 & Relationship Building & .627 & .983 \\
\hline 65 & Relationship Building & .651 & .710 \\
\hline 62 & Relationship Building & .694 & .871 \\
\hline 68 & Relationship Building & .681 & .728 \\
\hline 57 & Relationship Building & .552 & .779 \\
\hline 67 & Relationship Building & .596 & .551 \\
\hline 56 & Relationship Building & .511 & .697 \\
\hline 58 & Relationship Building & .542 & .501 \\
\hline 95 & Relationship Building & .448 & .660 \\
\hline 61 & Relationship Building & .393 & .402 \\
\hline 85 & Going Places & .497 & 1.000 \\
\hline 86 & Going Places & .458 & .638 \\
\hline 91 & Going Places & .556 & .907 \\
\hline 97 & Going Places & .584 & 1.151 \\
\hline 96 & Going Places & .591 & .996 \\
\hline 99 & Going Places & .583 & .662 \\
\hline 100 & Going Places & .620 & .668 \\
\hline 105 & Going Places & .649 & .779 \\
\hline 98 & Going Places & .692 & .867 \\
\hline 104 & Going Places & .668 & .719 \\
\hline 103 & Going Places & .671 & .890 \\
\hline 102 & Going Places & .735 & 1.007 \\
\hline 106 & Caretaking & .510 & 1.000 \\
\hline 109 & Caretaking & .311 & .342 \\
\hline 84 & Caretaking & .468 & 1.155 \\
\hline 93 & Caretaking & .507 & 1.267 \\
\hline 94 & Caretaking & .601 & 1.200 \\
\hline 111 & Caretaking & .438 & .819 \\
\hline 87 & Caretaking & .454 & 1.099 \\
\hline 90 & Caretaking & .588 & .909 \\
\hline 89 & Caretaking & .659 & 1.264 \\
\hline
\end{tabular}


Accessing Model Path Estimates

\begin{tabular}{llrr}
\hline Item & Factor & $\begin{array}{r}\text { Standardized } \\
\text { Estimates }\end{array}$ & $\begin{array}{r}\text { Unstandardized } \\
\text { Estimates }\end{array}$ \\
\hline 92 & Caretaking & .728 & 1.451 \\
69 & Violence & .747 & 1.000 \\
77 & Violence & .773 & 1.049 \\
76 & Violence & .742 & 1.152 \\
63 & Violence & .727 & 1.336 \\
74 & Violence & .681 & 1.065 \\
71 & Violence & .567 & .560 \\
73 & Violence & .555 & 1.026 \\
64 & Violence & .554 & 1.128 \\
54 & Cigarettes/Alcohol & .584 & 1.000 \\
53 & Cigarettes/Alcohol & .520 & 1.518 \\
\hline
\end{tabular}

Note. All paths are significant at the .001 level 
Table 8.

Gaining trust exploratory factor loadings

\begin{tabular}{|c|c|c|c|c|c|c|}
\hline Item & 1 & 2 & 3 & 4 & 5 & 6 \\
\hline give them a lot of attention & .790 & .049 & .011 & -.073 & -.050 & .015 \\
\hline spend a lot of time with them & .784 & .069 & .019 & -.074 & -.101 & -.045 \\
\hline play with them & .741 & .069 & -.042 & -.081 & .008 & .008 \\
\hline do what they like to do & .725 & .120 & .022 & -.108 & -.005 & .005 \\
\hline touch them non-sexually & .589 & .041 & -.095 & -.086 & -.049 & .260 \\
\hline $\begin{array}{l}\text { let them decide what you will do } \\
\text { together }\end{array}$ & .450 & .102 & .032 & -.118 & -.068 & .262 \\
\hline tell them they're special & .435 & .098 & -.044 & -.220 & -.087 & .322 \\
\hline $\begin{array}{l}\text { try to form real friendships } \\
\text { before sexual abuse }\end{array}$ & .430 & .058 & .091 & .001 & -.003 & .198 \\
\hline $\begin{array}{l}\text { imagine sexual abuse before it } \\
\text { began }\end{array}$ & .384 & -.013 & .028 & .037 & .272 & .188 \\
\hline $\begin{array}{l}\text { trick them into feeling safe with } \\
\text { you }\end{array}$ & .382 & .050 & .010 & -.134 & .278 & .137 \\
\hline $\begin{array}{l}\text { began sexual abuse before } \\
\text { mentioning sex }\end{array}$ & .364 & -.061 & .033 & .088 & .176 & -.017 \\
\hline $\begin{array}{l}\text { be like a parent before sexual } \\
\text { abuse }\end{array}$ & .334 & .054 & -.026 & -.137 & -.091 & .281 \\
\hline $\begin{array}{l}\text { protect them from people who } \\
\text { might hurt them }\end{array}$ & .325 & .127 & -.010 & -.291 & -.168 & .256 \\
\hline say you know one of their friends & .016 & .849 & .066 & .072 & -.002 & -.067 \\
\hline $\begin{array}{l}\text { say you know one of their } \\
\text { parents }\end{array}$ & .084 & .818 & -.058 & .073 & -.063 & -.066 \\
\hline $\begin{array}{l}\text { say you know one of their } \\
\text { relatives }\end{array}$ & .051 & .771 & .006 & .040 & -.112 & -.045 \\
\hline $\begin{array}{l}\text { have another child talk about } \\
\text { having fun with you }\end{array}$ & -.074 & .614 & .084 & .005 & .200 & .030 \\
\hline $\begin{array}{l}\text { let them see you with another } \\
\text { child they know }\end{array}$ & .143 & .564 & .026 & -.079 & -.058 & .019 \\
\hline have their friend say to trust you & -.043 & .508 & .107 & -.034 & .162 & .112 \\
\hline $\begin{array}{l}\text { say they shouldn't talk to } \\
\text { strangers, but you're ok }\end{array}$ & -.028 & .481 & -.011 & -.111 & .077 & .076 \\
\hline offer to help them & .068 & .346 & -.047 & -.224 & .220 & .102 \\
\hline $\begin{array}{l}\text { talk to them about another } \\
\text { abuser they know }\end{array}$ & -.031 & .319 & .117 & -.024 & .102 & .107 \\
\hline give them cigarettes & .023 & .012 & .964 & -.002 & -.068 & -.125 \\
\hline let them smoke cigarettes & .020 & .061 & .893 & .026 & -.010 & -.079 \\
\hline give them beer or liquor & -.077 & -.042 & .626 & -.024 & -.044 & .086 \\
\hline show them pornography & .104 & .106 & .168 & -.054 & .110 & .055 \\
\hline give them toys & .223 & -.002 & -.047 & -.755 & .110 & -.235 \\
\hline give them money & -.079 & -.033 & .176 & -.716 & .013 & .050 \\
\hline give them candy or fav food & .255 & .004 & -.012 & -.704 & .151 & -.175 \\
\hline give them privileges or rewards & .186 & -.057 & .001 & -.629 & .020 & .112 \\
\hline
\end{tabular}


Gaining trust exploratory factor loadings

\begin{tabular}{|c|c|c|c|c|c|c|}
\hline Item & 1 & 2 & 3 & 4 & 5 & 6 \\
\hline give them other gifts & -.058 & -.016 & .039 & -.562 & .023 & .102 \\
\hline $\begin{array}{l}\text { let them see you give something } \\
\text { to another child }\end{array}$ & -.023 & .273 & .056 & -.441 & -.037 & .001 \\
\hline $\begin{array}{l}\text { give money to others in their } \\
\text { family }\end{array}$ & -.081 & .163 & .021 & -.436 & -.170 & .139 \\
\hline take them places & .301 & .082 & .120 & -.378 & -.085 & .107 \\
\hline $\begin{array}{l}\text { stick up for them against their } \\
\text { friends }\end{array}$ & .071 & .137 & .036 & -.364 & .008 & .284 \\
\hline $\begin{array}{l}\text { let them do something else they } \\
\text { aren't supposed to }\end{array}$ & .217 & -.068 & .240 & -.266 & .138 & .180 \\
\hline $\begin{array}{l}\text { act like someone they like or } \\
\text { trust }\end{array}$ & -.077 & .280 & -.031 & -.137 & .431 & .021 \\
\hline ask them for help & -.031 & .343 & .015 & .001 & .379 & .043 \\
\hline $\begin{array}{l}\text { pretend to be friends before } \\
\text { sexual abuse }\end{array}$ & .247 & .092 & .029 & -.041 & .322 & .125 \\
\hline $\begin{array}{l}\text { test them for secrecy before } \\
\text { sexual abuse }\end{array}$ & .129 & .034 & .000 & -.238 & .269 & .151 \\
\hline treat them like adults & .153 & .001 & .071 & -.176 & -.124 & .533 \\
\hline $\begin{array}{l}\text { pretend to be romantically } \\
\text { involved before sexual abuse }\end{array}$ & -.010 & .018 & .082 & -.015 & .146 & .508 \\
\hline say loving, caring things to them & .367 & .079 & -.086 & -.206 & -.050 & .413 \\
\hline stick up for them against a parent & .073 & .096 & -.018 & -.362 & -.143 & .404 \\
\hline tell them personal things & .257 & .090 & .034 & -.168 & .044 & .360 \\
\hline tell them only you love them & .008 & .164 & -.052 & -.232 & .098 & .341 \\
\hline talk like their age & .135 & .174 & .102 & -.105 & .095 & .316 \\
\hline $\begin{array}{l}\text { talk to them about sex before } \\
\text { sexual abuse }\end{array}$ & .044 & -.002 & .027 & .062 & .017 & .218 \\
\hline
\end{tabular}

Note. 1. Kindness; 2. Trust by Association; 3. Cigarettes and Alcohol; 4. Bribes;

5. Manipulation; 6. Treat like a Peer. Loadings above .3 are bolded. 
Table 9.

Gaining Trust Model Path Estimates

\begin{tabular}{|c|c|c|c|}
\hline Item & Factor & $\begin{array}{r}\text { Standardized } \\
\text { Estimates } \\
\end{array}$ & $\begin{array}{r}\text { Unstandardized } \\
\text { Estimates } \\
\end{array}$ \\
\hline Kindness & Gaining Trust & .883 & .812 \\
\hline Association & Gaining Trust & .593 & .139 \\
\hline Bribes & Gaining Trust & .857 & .710 \\
\hline Cigarettes/Alcohol & Gaining Trust & .195 & .057 \\
\hline Treat like peer & Gaining Trust & .976 & .622 \\
\hline Manipulation) & Gaining Trust & .613 & .396 \\
\hline 119 & Kindness & .809 & 1.000 \\
\hline 118 & Kindness & .762 & .943 \\
\hline 145 & Kindness & .802 & .991 \\
\hline 146 & Kindness & .826 & 1.057 \\
\hline 142 & Kindness & .784 & 1.011 \\
\hline 143 & Kindness & .724 & .915 \\
\hline 121 & Kindness & .786 & .620 \\
\hline 161 & Kindness & .573 & .835 \\
\hline 168 & Kindness & .500 & .383 \\
\hline 136 & Kindness & .611 & .955 \\
\hline 166 & Kindness & .294 & 1.000 \\
\hline 144 & Kindness & .700 & .933 \\
\hline 125 & Bribes & .738 & 1.054 \\
\hline 128 & Bribes & .699 & 1.100 \\
\hline 124 & Bribes & .754 & .710 \\
\hline 127 & Bribes & .763 & .555 \\
\hline 132 & Bribes & .574 & .986 \\
\hline 126 & Bribes & .561 & .821 \\
\hline 123 & Bribes & .684 & .521 \\
\hline 148 & Bribes & .637 & 1.000 \\
\hline 133 & Bribes & .517 & .915 \\
\hline 135 & Treat like peer & .599 & 1.288 \\
\hline 122 & Treat like peer & .592 & 1.131 \\
\hline 120 & Treat like peer & .703 & 1.543 \\
\hline 147 & Treat like peer & .664 & .771 \\
\hline 141 & Treat like peer & .789 & 1.235 \\
\hline 164 & Treat like peer & .488 & 1.000 \\
\hline 134 & Treat like peer & .685 & 1.558 \\
\hline 130 & Cigarettes/Alcohol & .628 & 1.838 \\
\hline 139 & Cigarettes/Alcohol & .828 & 1.000 \\
\hline 129 & Cigarettes/Alcohol & .982 & .552 \\
\hline 162 & Manipulation & .527 & .758 \\
\hline 156 & Manipulation & .570 & 1.000 \\
\hline 155 & Manipulation & .635 & 2.450 \\
\hline
\end{tabular}


Gaining Trust Model Path Estimates

\begin{tabular}{llrr}
\hline Item & Factor & $\begin{array}{r}\text { Standardized } \\
\text { Estimates }\end{array}$ & $\begin{array}{r}\text { Unstandardized } \\
\text { Estimates }\end{array}$ \\
\hline 138 & Association & .408 & 2.197 \\
157 & Association & .569 & 2.354 \\
153 & Association & .573 & 2.699 \\
137 & Association & .636 & 1.962 \\
149 & Association & .650 & 2.996 \\
154 & Association & .680 & 2.722 \\
150 & Association & .755 & 2.602 \\
152 & Association & .806 & 1.050 \\
151 & Association & .741 & .750 \\
\hline
\end{tabular}

Note. All paths are significant at the .001 level 
Table 10

Gaining Cooperation Exploratory Factor Loadings

\begin{tabular}{|c|c|c|c|c|c|c|}
\hline \multicolumn{7}{|l|}{ Item } \\
\hline & 1 & 2 & 3 & 4 & 5 & 6 \\
\hline $\begin{array}{l}\text { say you will love } \\
\text { them more if they } \\
\text { do this with you }\end{array}$ & .546 & .029 & .119 & .311 & .160 & -.091 \\
\hline $\begin{array}{l}\text { say they don't love } \\
\text { you if they don't do } \\
\text { sex things }\end{array}$ & .506 & .100 & .086 & .203 & .115 & -.012 \\
\hline $\begin{array}{l}\text { say you will 'teach' } \\
\text { them something }\end{array}$ & .427 & .030 & .057 & .149 & .351 & .003 \\
\hline $\begin{array}{l}\text { say you will make } \\
\text { up things to tell on } \\
\text { them }\end{array}$ & .423 & .342 & .047 & .146 & -.128 & .065 \\
\hline $\begin{array}{l}\text { say you will tell on } \\
\text { them about having } \\
\text { sex w/ you }\end{array}$ & .400 & .235 & .050 & .084 & -.036 & .035 \\
\hline $\begin{array}{l}\text { tell them their } \\
\text { friends have already } \\
\text { had sex }\end{array}$ & .358 & .011 & .191 & .131 & .065 & .227 \\
\hline $\begin{array}{l}\text { say you will hit } \\
\text { them if they don't } \\
\text { do it }\end{array}$ & -.115 & .825 & -.077 & .036 & .034 & .049 \\
\hline hurt them & -.092 & .742 & -.093 & -.025 & .059 & .107 \\
\hline $\begin{array}{l}\text { use force to make } \\
\text { them do sex things }\end{array}$ & .010 & .707 & -.055 & -.054 & .058 & -.018 \\
\hline $\begin{array}{l}\text { make them feel like } \\
\text { there is nothing to } \\
\text { do to stop it }\end{array}$ & .055 & .663 & .001 & .072 & .117 & -.141 \\
\hline $\begin{array}{l}\text { say you will hurt } \\
\text { their siblings }\end{array}$ & -.006 & .611 & .199 & -.027 & -.067 & .131 \\
\hline $\begin{array}{l}\text { say you will hurt } \\
\text { their mother }\end{array}$ & -.053 & .602 & .136 & -.054 & -.023 & .163 \\
\hline $\begin{array}{l}\text { say you will kill } \\
\text { them }\end{array}$ & -.106 & .555 & .088 & .044 & -.062 & .037 \\
\hline $\begin{array}{l}\text { hope they thought } \\
\text { you'd hurt them }\end{array}$ & .197 & .477 & -.026 & .061 & .023 & -.038 \\
\hline $\begin{array}{l}\text { hope they thought } \\
\text { you'd hurt a family } \\
\text { member }\end{array}$ & .159 & .459 & .079 & -.069 & .026 & .124 \\
\hline
\end{tabular}


hope they thought you'd get them in trouble buy them bathing suits

buy them

underwear or sleepwear

talk pics or vids of them with clothes off

show them pics or vids of you with clothes off

take pics or vids of them with clothes

on

have them watch you do sex things with adults

show them media $\mathrm{w} /$ adults doing sex things $\mathrm{w} /$ kids

say you would hire them for a job give them money just after sexual abuse give them toys just after sexual abuse give them money sometimes

give them gifts sometimes give them candy just after sexualx abuse give them privileges or rewards just after sexual abuse

say you will take them places

give them other gifts just after sexual abuse say you will spend more time with them buy them other clothes give non-sexual attention

\begin{tabular}{|c|c|c|c|c|c|}
\hline .286 & .376 & -.014 & .070 & .065 & -.028 \\
\hline -105 & .061 & .700 & .143 & .045 & -.066 \\
\hline -.106 & .003 & .653 & .159 & .109 & -.134 \\
\hline .104 & -.007 & .623 & -.122 & .028 & .052 \\
\hline .205 & .082 & .573 & -.114 & -.066 & .072 \\
\hline-.079 & -.022 & .550 & .006 & .135 & .050 \\
\hline .005 & .041 & .403 & -.026 & -.023 & .184 \\
\hline .198 & .094 & .373 & -.106 & -.085 & .183 \\
\hline .047 & -.048 & .286 & .149 & -.036 & .205 \\
\hline-.010 & .004 & -.034 & .850 & -.113 & .117 \\
\hline .104 & .119 & -.082 & .746 & -.048 & -.014 \\
\hline-.114 & -.034 & .054 & .686 & .140 & .125 \\
\hline -.105 & .004 & .035 & .671 & .270 & .026 \\
\hline .141 & .068 & -.063 & .655 & .041 & .036 \\
\hline .140 & -.012 & -.057 & .537 & .245 & .076 \\
\hline .271 & .005 & .034 & .537 & .176 & .033 \\
\hline .002 & .000 & .178 & .470 & .014 & -.041 \\
\hline .313 & .054 & .044 & .467 & .216 & -.021 \\
\hline-.1 & -.067 & .413 & .449 & .152 & -.095 \\
\hline -.167 & .072 & .003 & -.017 & .828 & -.014 \\
\hline
\end{tabular}


touch them non-

sexually

say nice things

about them

say loving things

touch them more

and more

start sexual abuse

like no big thing

get them curious

about sex

get them sexually

excited

start sexual abuse

when they were

upset

say how special they

are to be doing this

with you

talk more and more

about sex

wear less clothes

and tell child to

wear less

have them join in

sex between you

and another kid

have them watch

you do sexual things

with other kids

have their friend,

who you've been

sexual involved

with, say it's ok

have them do sexual

things with other

children

give them beer or

liquor just after

sexual abuse

give them cigarettes

just after sexual

abuse

show them media

$\mathrm{w} /$ naked adults

talk about another

abuser with whom

they've been

involved

\begin{tabular}{|c|c|c|c|c|c|}
\hline-.129 & .075 & .089 & .038 & .798 & -.086 \\
\hline-.078 & .026 & .066 & .131 & .787 & -.048 \\
\hline .002 & .016 & .108 & .133 & .694 & -.086 \\
\hline .148 & .061 & .029 & .025 & .568 & .100 \\
\hline .100 & .082 & -.075 & -.025 & .557 & .108 \\
\hline .318 & -.126 & -.025 & .057 & .483 & .213 \\
\hline .237 & -.120 & .030 & .013 & .472 & .245 \\
\hline .107 & .052 & .077. & .139 & .404 & .135 \\
\hline .339 & -.054 & .089 & .275 & .344 & -.007 \\
\hline .335 & -.106 & .026 & .031 & .343 & .280 \\
\hline .151 & -.031 & .232 & .088 & .332 & .098 \\
\hline-.017 & .027 & -.038 & -.031 & .097 & .733 \\
\hline-.015 & .073. & -.028 & -.085 & .131 & .641 \\
\hline .075 & .005 & .056 & .049 & .026 & .589 \\
\hline .018 & .063. & .064 & -.029 & .027 & .574 \\
\hline -.133 & .104 & .054 & .167 & -.101 & .442 \\
\hline-.069 & .099 & .046 & .168 & -.113 & .405 \\
\hline .236 & -.056 & .089 & .034 & .109 & .332 \\
\hline-.016 & .071 & 179 & .075 & .023 & .308 \\
\hline
\end{tabular}

Note. 1. Manipulation; 2. Violence; 3. Use of Pornography; 4. Bribes;

5. Desensitization; 6. Participation. Loadings above .3 are bold 
Table 11.

Cooperation Model Path Estimates

\begin{tabular}{|c|c|c|c|}
\hline Item & Factor & $\begin{array}{r}\text { Standardized } \\
\text { Estimates } \\
\end{array}$ & $\begin{array}{c}\text { Unstandardized } \\
\text { Estimates } \\
\end{array}$ \\
\hline Bribes & Gaining Cooperation & .835 & .444 \\
\hline Violence & Gaining Cooperation & .452 & .228 \\
\hline Desensitization & Gaining Cooperation & .809 & .679 \\
\hline Participation & Gaining Cooperation & .522 & .130 \\
\hline Pornography & Gaining Cooperation & .608 & .111 \\
\hline Manipulation & Gaining Cooperation & .899 & .464 \\
\hline 228 & Desensitization & .667 & 1.000 \\
\hline 227 & Desensitization & .701 & 1.057 \\
\hline 229 & Desensitization & .762 & 1.126 \\
\hline 226 & Desensitization & .620 & 1.224 \\
\hline 220 & Desensitization & .710 & 1.011 \\
\hline 222 & Desensitization & .622 & .923 \\
\hline 224 & Desensitization & .727 & 1.047 \\
\hline 225 & Desensitization & .688 & .998 \\
\hline 223 & Desensitization & .627 & .791 \\
\hline 233 & Desensitization & .672 & .861 \\
\hline 218 & Desensitization & .644 & .861 \\
\hline 219 & Desensitization & .595 & .680 \\
\hline 243 & Bribes & .577 & 1.000 \\
\hline 237 & Bribes & .757 & 1.575 \\
\hline $238 \mathrm{~h}$ & Bribes & .529 & .787 \\
\hline 236 & Bribes & .787 & 1.596 \\
\hline $238 g$ & Bribes & .733 & 1.594 \\
\hline $238 a$ & Bribes & .723 & 1.602 \\
\hline 231 & Bribes & .791 & 1.735 \\
\hline 230 & Bribes & .740 & 1.606 \\
\hline $238 c$ & Bribes & .729 & 1.506 \\
\hline $238 b$ & Bribes & .738 & 1.501 \\
\hline 270 & Violence & .809 & 1.000 \\
\hline 290 & Violence & .735 & .677 \\
\hline 295 & Violence & 689 & 1.027 \\
\hline 269 & Violence & .668 & 1.165 \\
\hline 275 & Violence & .643 & .503 \\
\hline 282 & Violence & .532 & .352 \\
\hline 280 & Violence & .607 & .527 \\
\hline 296 & Violence & .543 & .854 \\
\hline 297 & Violence & .543 & .574 \\
\hline 298 & Violence & .460 & .728 \\
\hline 221 & Manipulation & .648 & 1.000 \\
\hline 265 & Manipulation & .553 & .808 \\
\hline
\end{tabular}


Cooperation Model Path Estimates

\begin{tabular}{llrr}
\hline Item & Factor & $\begin{array}{r}\text { Standardized } \\
\text { Estimates }\end{array}$ & $\begin{array}{r}\text { Unstandardized } \\
\text { Estimates }\end{array}$ \\
\hline 266 & Manipulation & .557 & .868 \\
234 & Manipulation & .559 & 1.690 \\
294 & Manipulation & .755 & 1.263 \\
235 & Manipulation & .793 & 1.560 \\
240 & Participation & .442 & 1.000 \\
257 & Participation & .399 & 1.480 \\
$238 \mathrm{f}$ & Participation & .399 & .836 \\
$238 \mathrm{~d}$ & Participation & .398 & .691 \\
251 & Participation & .718 & 1.484 \\
239 & Participation & .653 & 1.477 \\
245 & Participation & .742 & 1.513 \\
252 & Participation & .822 & 1.703 \\
259 & Pornography & .476 & 1.000 \\
247 & Pornography & .504 & 1.309 \\
248 & Pornography & .612 & 2.282 \\
244 & Pornography & .643 & 1.538 \\
254 & Pornography & .674 & 1.915 \\
242 & Pornography & .639 & 2.317 \\
241 & Pornography & .661 & 2.104 \\
\hline
\end{tabular}

Note. All paths are significant at the .001 level 
Table 12.

Sexual Abuse Loadings

\begin{tabular}{|c|c|c|c|c|c|}
\hline Item & 1 & 2 & 3 & 4 & 5 \\
\hline masturbate you for awhile & .800 & -.047 & .036 & .047 & -.012 \\
\hline $\begin{array}{l}\text { put their mouth or tongue on } \\
\text { your penis }\end{array}$ & .777 & .046 & .035 & -.127 & .039 \\
\hline touch your penis & .757 & .033 & .010 & -.008 & -.129 \\
\hline $\begin{array}{l}\text { masturbate you to } \\
\text { ejaculation/orgasm }\end{array}$ & .603 & -.007 & .006 & .023 & .101 \\
\hline rub them against you & .474 & -.017 & .023 & .350 & .021 \\
\hline $\begin{array}{l}\text { put your mouth or tongue on } \\
\text { their vagina or penis }\end{array}$ & .375 & .060 & -.083 & .288 & .183 \\
\hline $\begin{array}{l}\text { put your penis into their } \\
\text { vagina }\end{array}$ & .019 & .773 & .168 & -.048 & -.072 \\
\hline $\begin{array}{l}\text { try to put your penis into } \\
\text { their vagina }\end{array}$ & .098 & .760 & .141 & .060 & -.179 \\
\hline $\begin{array}{l}\text { put your finger in their } \\
\text { vagina }\end{array}$ & -.030 & .610 & -.084 & .162 & .048 \\
\hline put an object in their vagina & .014 & .411 & -.017 & -.056 & .212 \\
\hline touch their breasts/nipples & .057 & .401 & -.121 & .362 & -.071 \\
\hline $\begin{array}{l}\text { try to put your penis into } \\
\text { their anus }\end{array}$ & .101 & .033 & .761 & .143 & .110 \\
\hline $\begin{array}{l}\text { put your penis into their } \\
\text { anus }\end{array}$ & .043 & .132 & .693 & .065 & .153 \\
\hline $\begin{array}{l}\text { rub them sexually with them } \\
\text { knowing }\end{array}$ & -.012 & -.009 & .038 & .738 & -.043 \\
\hline touch their buttocks & .052 & .037 & .108 & .638 & -.028 \\
\hline touch their vagina or penis & .015 & .100 & -.130 & .567 & .116 \\
\hline $\begin{array}{l}\text { rub your penis against their } \\
\text { bodies }\end{array}$ & .263 & .081 & .171 & .468 & -.099 \\
\hline $\begin{array}{l}\text { rub against them sexually } \\
\text { w/o them knowing }\end{array}$ & -.021 & -.007 & .076 & .435 & .007 \\
\hline $\begin{array}{l}\text { masturbate them (not to } \\
\text { ejaculation/orgasm) }\end{array}$ & .211 & -.015 & -.107 & .371 & .227 \\
\hline $\begin{array}{l}\text { put their finger or object in } \\
\text { your anus }\end{array}$ & -.007 & -.069 & .006 & .021 & .598 \\
\hline put their penis in your anus & .112 & -.193 & .177 & .031 & .472 \\
\hline $\begin{array}{l}\text { put their finger or object into } \\
\text { their anus }\end{array}$ & -.055 & .100 & .232 & .016 & .406 \\
\hline touch your butt & .293 & -.012 & .083 & .123 & .330 \\
\hline $\begin{array}{l}\text { put your mouth on their } \\
\text { anus }\end{array}$ & .075 & .043 & .055 & .158 & .303 \\
\hline $\begin{array}{l}\text { masturbate them to } \\
\text { ejaculation/orgasm }\end{array}$ & .157 & .115 & -.100 & .158 & .202 \\
\hline
\end{tabular}

Note. 1. Self-serving Abuse; 2. Abuse of a Female; 3. Anal Penetration; 4. Sexual Touch; 5. Buttock related abuse. 
Table 13.

Sexual Abuse Model Path Estimates

\begin{tabular}{|c|c|c|c|}
\hline Item & Factor & $\begin{array}{r}\text { Standardized } \\
\text { Estimates } \\
\end{array}$ & $\begin{array}{r}\text { Unstandardized } \\
\text { Estimates } \\
\end{array}$ \\
\hline Female Victim & Sexual Abuse & .497 & .388 \\
\hline Buttock Related & Sexual Abuse & .713 & .158 \\
\hline Anal Penetration & Sexual Abuse & .580 & .529 \\
\hline Self-Serving & Sexual Abuse & .881 & .790 \\
\hline Sexual Touch & Sexual Abuse & .863 & .677 \\
\hline 182 & Self-Serving & .653 & .932 \\
\hline 197 & Self-Serving & .711 & .947 \\
\hline 199 & Self-Serving & .664 & .780 \\
\hline 195 & Self-Serving & .691 & 1.090 \\
\hline 200 & Self-Serving & .718 & .963 \\
\hline 198 & Self-Serving & .762 & 1.000 \\
\hline 179 & Sexual Touch & .580 & .857 \\
\hline 190 & Sexual Touch & .406 & .591 \\
\hline 180 & Sexual Touch & .707 & 1.110 \\
\hline 177 & Sexual Touch & .598 & .859 \\
\hline 176 & Sexual Touch & .523 & 1.068 \\
\hline 191 & Sexual Touch & .656 & 1.000 \\
\hline 189 & Female Victim & .772 & 1.000 \\
\hline 188 & Female Victim & .834 & 1.184 \\
\hline 183 & Female Victim & .638 & .980 \\
\hline 184 & Female Victim & .371 & .281 \\
\hline 175 & Female Victim & .517 & .806 \\
\hline 201 & Buttock Related & .544 & 1.000 \\
\hline 202 & Buttock Related & .543 & 1.456 \\
\hline 185 & Buttock Related & .402 & 1.128 \\
\hline 196 & Buttock Related & .685 & 2.963 \\
\hline 181 & Buttock Related & .482 & 1.985 \\
\hline 187 & Anal Penetration & .798 & .730 \\
\hline 186 & Anal Penetration & .938 & 1.000 \\
\hline
\end{tabular}

Note. All paths are significant at the .001 level 
Table 14.

Silencing Exploratory Factor Loadings

\begin{tabular}{|c|c|c|}
\hline & Bribes & Threats \\
\hline $\begin{array}{l}\text { say you cannot go places together if } \\
\text { anyone knew }\end{array}$ & .861 & -.036 \\
\hline $\begin{array}{l}\text { say you will take them places if they } \\
\text { don't tell }\end{array}$ & .856 & -.072 \\
\hline $\begin{array}{l}\text { say you cannot buy but them things if } \\
\text { anyone knew }\end{array}$ & .852 & -.067 \\
\hline $\begin{array}{l}\text { say you will spend more time together if } \\
\text { they don't tell }\end{array}$ & .837 & -.002 \\
\hline $\begin{array}{l}\text { say you will love them more if they don't } \\
\text { tell }\end{array}$ & .789 & .040 \\
\hline $\begin{array}{l}\text { say you will give privileges of if they } \\
\text { don't tell }\end{array}$ & .772 & .012 \\
\hline $\begin{array}{l}\text { say they would not get to see you } \\
\text { anymore }\end{array}$ & .718 & .036 \\
\hline $\begin{array}{l}\text { say you cannot spend time together if } \\
\text { anyone knew }\end{array}$ & .652 & -.010 \\
\hline say you would get in trouble if they told & .579 & .039 \\
\hline $\begin{array}{l}\text { say that you would not love them } \\
\text { anymore }\end{array}$ & .477 & .337 \\
\hline hope they wouldn't want to lose you & .425 & .218 \\
\hline $\begin{array}{l}\text { say their parents wouldn't love them } \\
\text { anymore (sex) }\end{array}$ & .050 & .713 \\
\hline hope they thought you would hurt them & -.131 & .699 \\
\hline $\begin{array}{l}\text { hope they thought you would get them } \\
\text { in trouble }\end{array}$ & .038 & .681 \\
\hline hope they thought it was their fault & .037 & .662 \\
\hline say people would think they are gay & -.037 & .573 \\
\hline hurt them as warning & -.098 & .524 \\
\hline $\begin{array}{l}\text { say you would tell on them about bad } \\
\text { behaviors }\end{array}$ & .312 & .493 \\
\hline take away love or affection as warning & .246 & .481 \\
\hline $\begin{array}{l}\text { say you would tell on them about their } \\
\text { sexual activity }\end{array}$ & .290 & .472 \\
\hline $\begin{array}{l}\text { hope their family didn't talk about } \\
\text { sexual things }\end{array}$ & .084 & .437 \\
\hline say they would get in trouble if they told & .346 & .366 \\
\hline $\begin{array}{l}\text { say their parents would not love them } \\
\text { anymore (told) }\end{array}$ & .142 & .366 \\
\hline
\end{tabular}


Table 15.

Silencing Model Path Estimates

\begin{tabular}{llrr}
\hline Item & Factor & $\begin{array}{r}\text { Standardized } \\
\text { Estimates }\end{array}$ & $\begin{array}{r}\text { Unstandardized } \\
\text { Estimates }\end{array}$ \\
\hline 303 & Bribes & .831 & .863 \\
307 & Bribes & .818 & .846 \\
308 & Bribes & .805 & .790 \\
304 & Bribes & .855 & .903 \\
305 & Bribes & .828 & .854 \\
302 & Bribes & .793 & .926 \\
313 & Bribes & .712 & .789 \\
306 & Bribes & .634 & .978 \\
300 & Bribes & .569 & .694 \\
310 & Bribes & .676 & .560 \\
335 & Bribes & .559 & .678 \\
329 & Threats & .732 & .531 \\
336 & Threats & .504 & .407 \\
337 & Threats & .674 & .601 \\
334 & Threats & .650 & .635 \\
328 & Threats & .526 & .321 \\
331 & Threats & .406 & .183 \\
312 & Threats & .741 & .658 \\
332 & Threats & .634 & .473 \\
311 & Threats & .711 & .575 \\
333 & Threats & .466 & .491 \\
301 & Threats & .639 & .614 \\
309 & Threats & .495 & .635 \\
\hline & Note. All paths are significant at the .001 level \\
& & &
\end{tabular}


Figure 1.

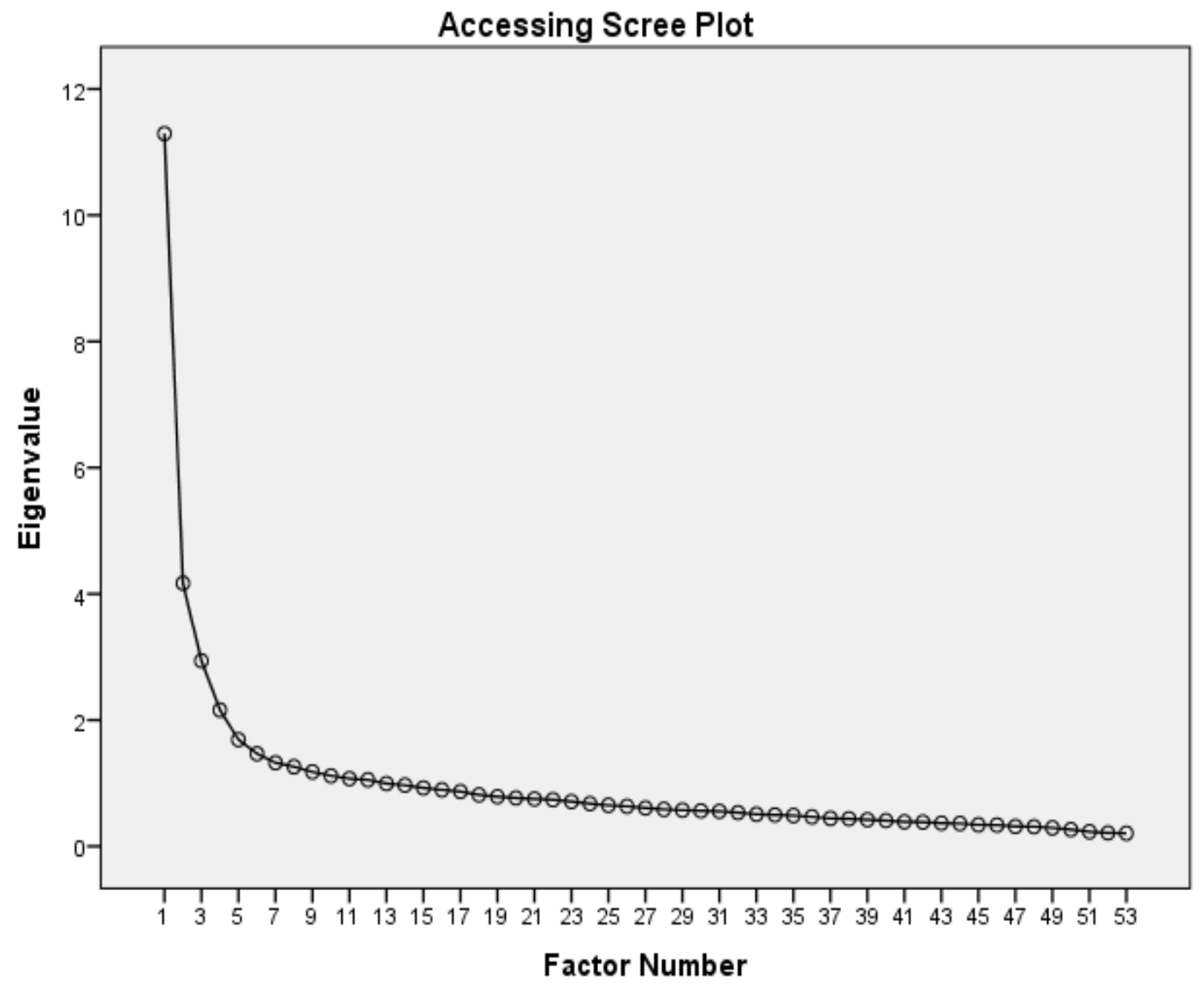




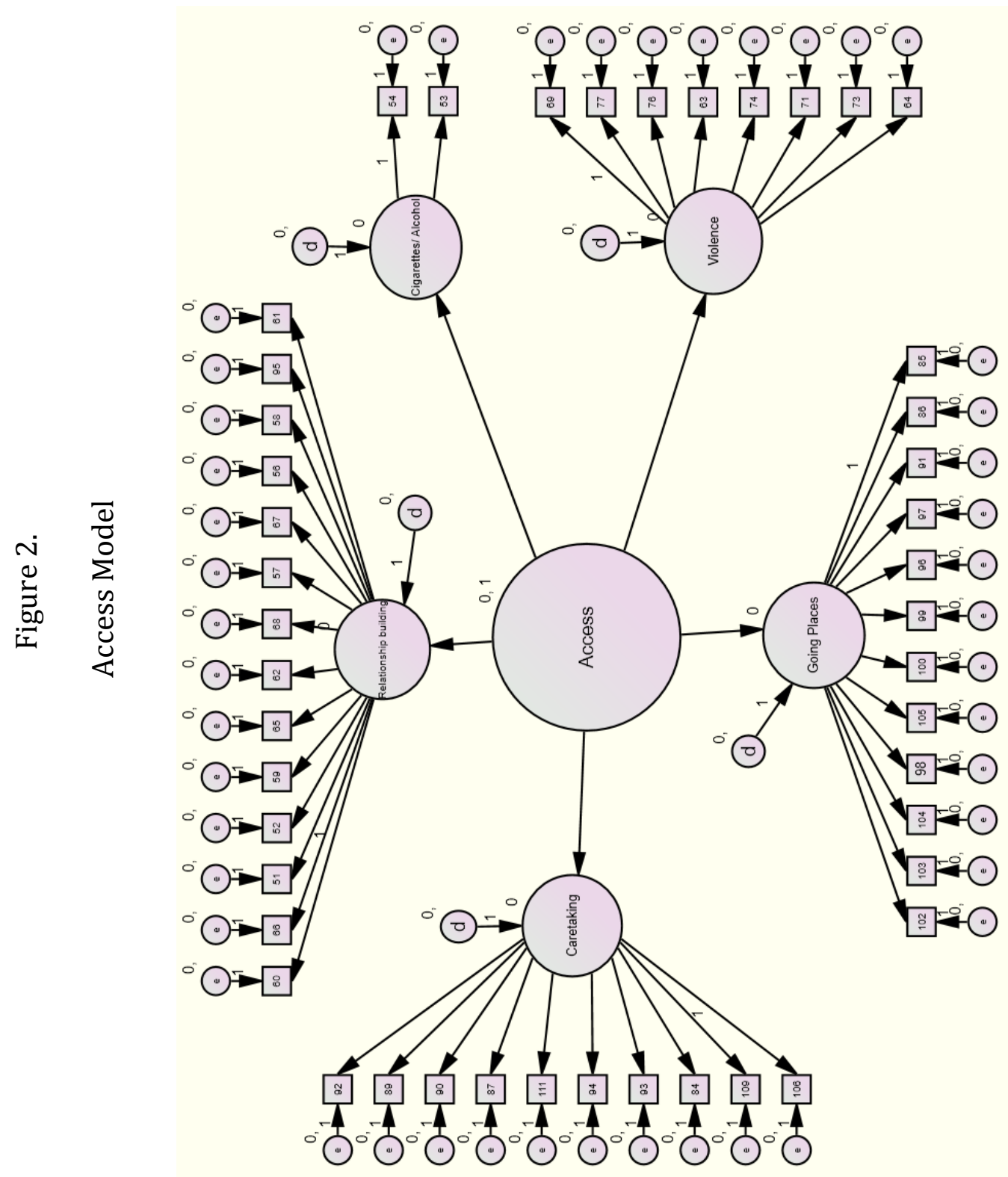


Figure 3.

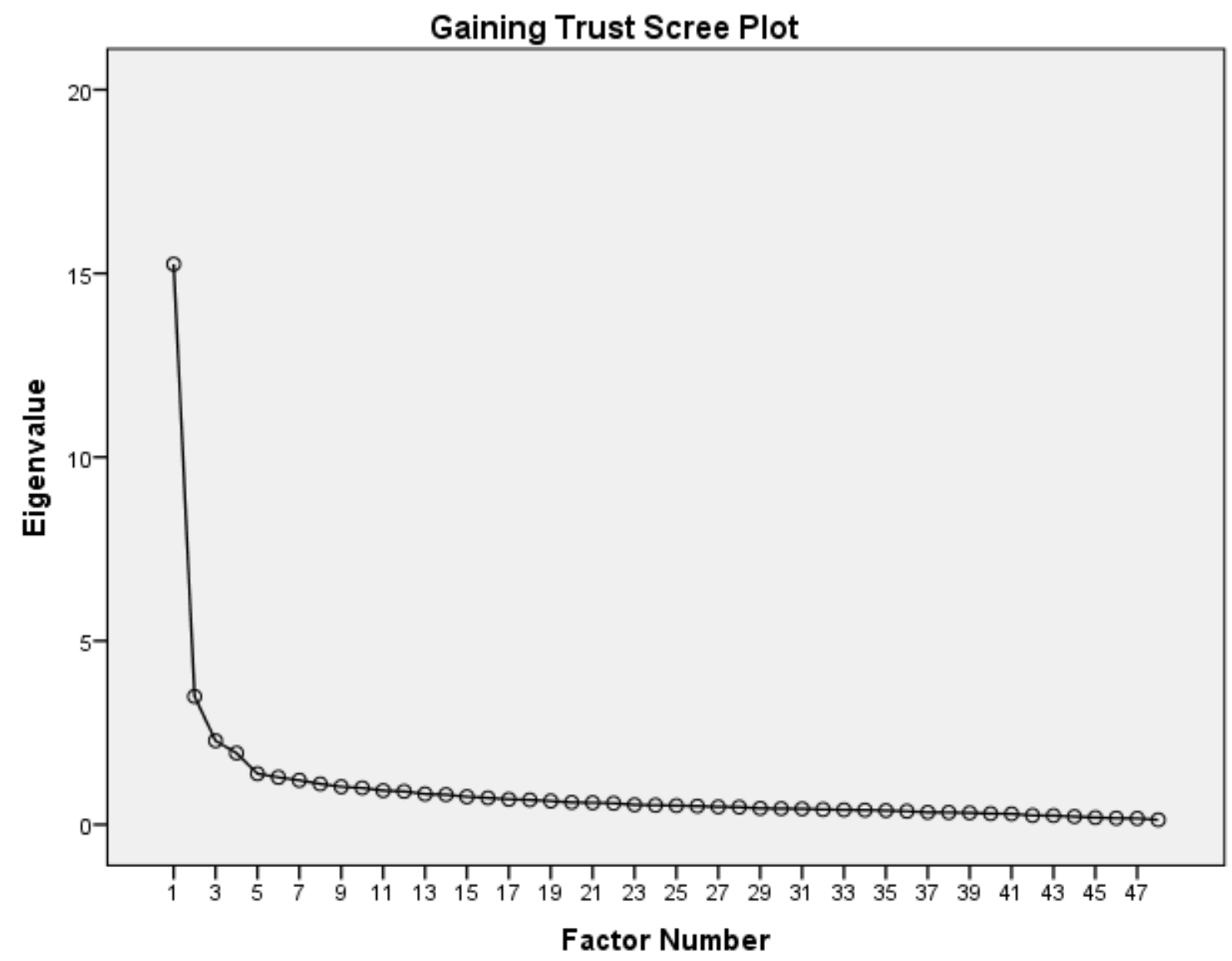




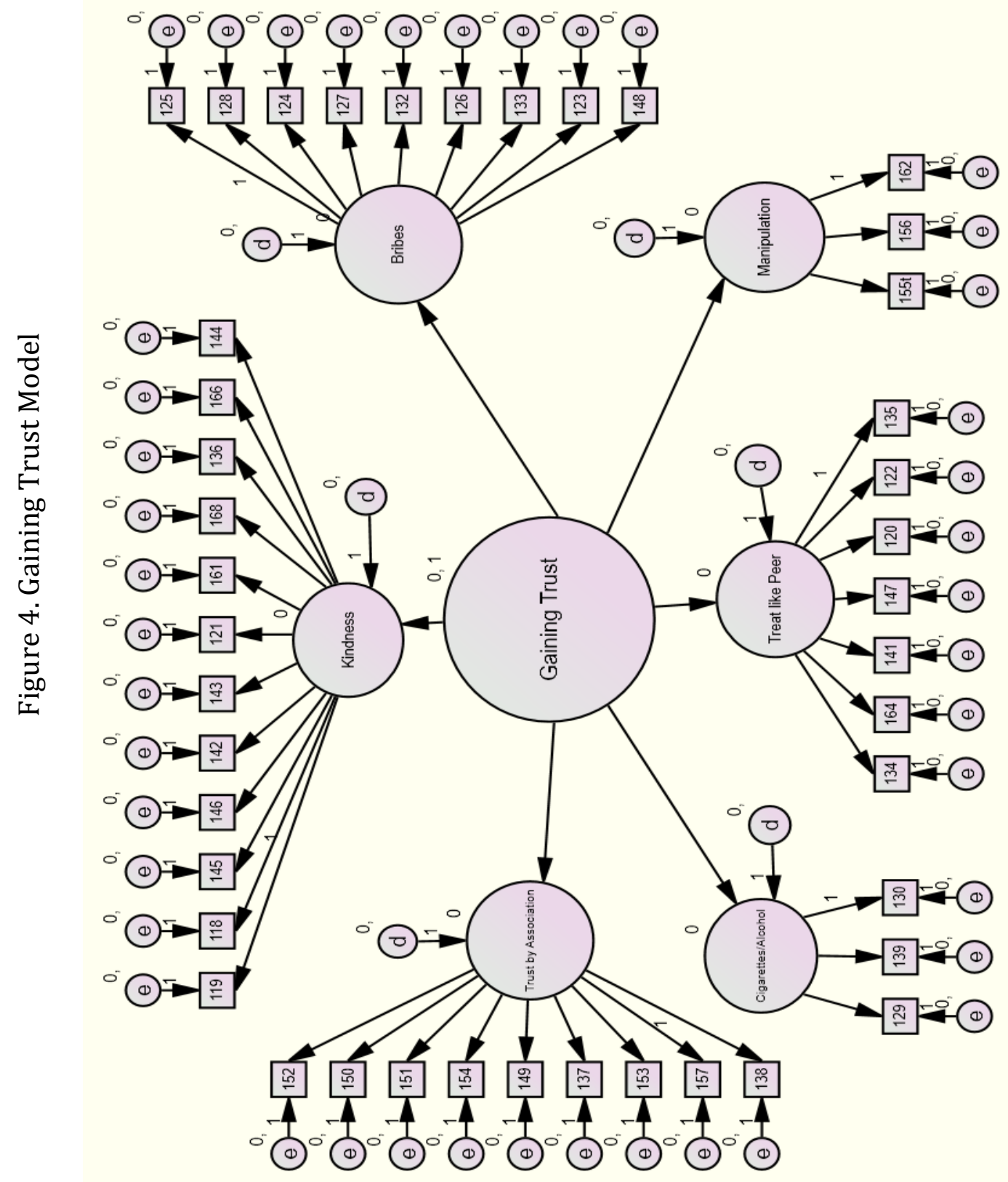


Figure 5.

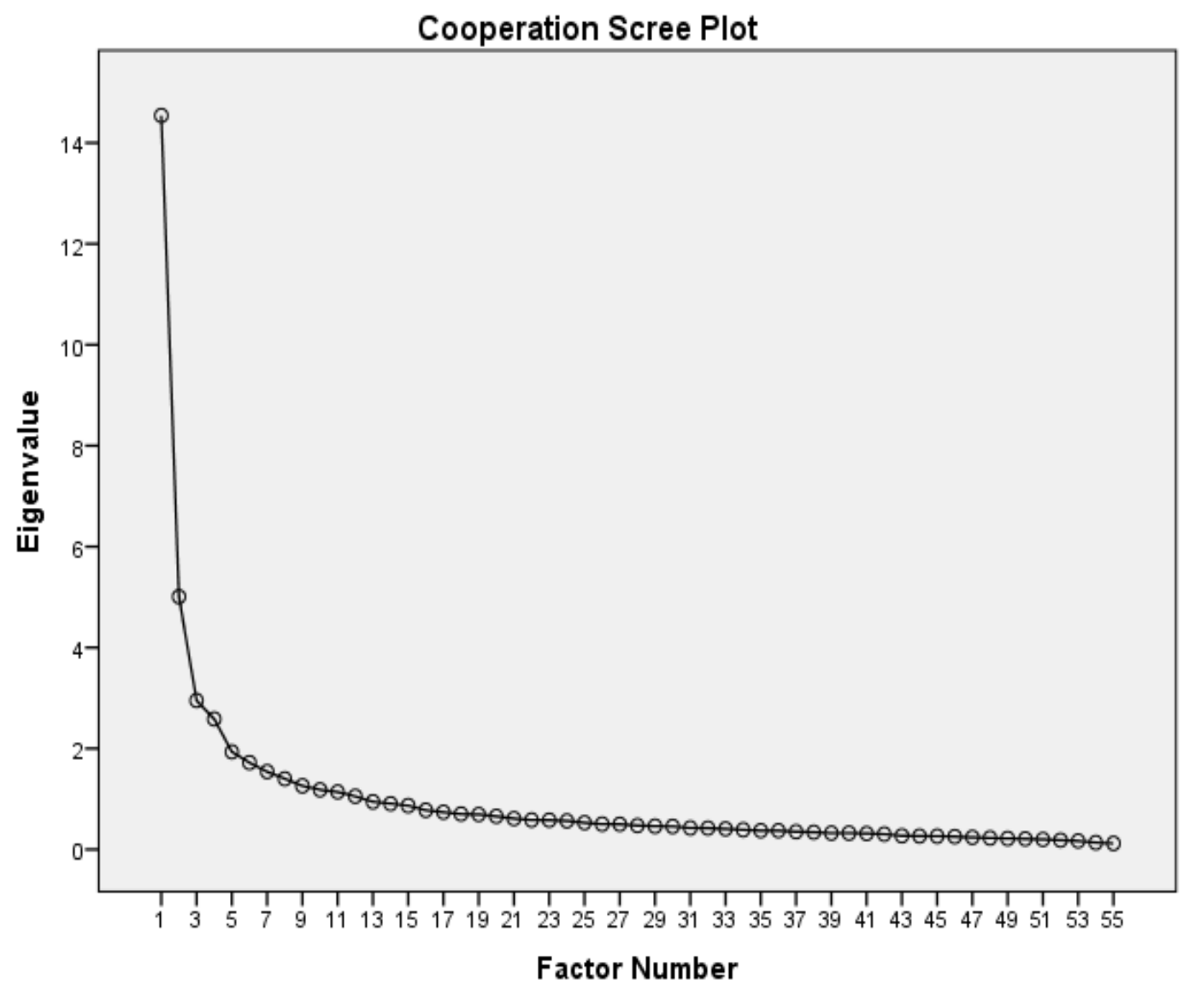




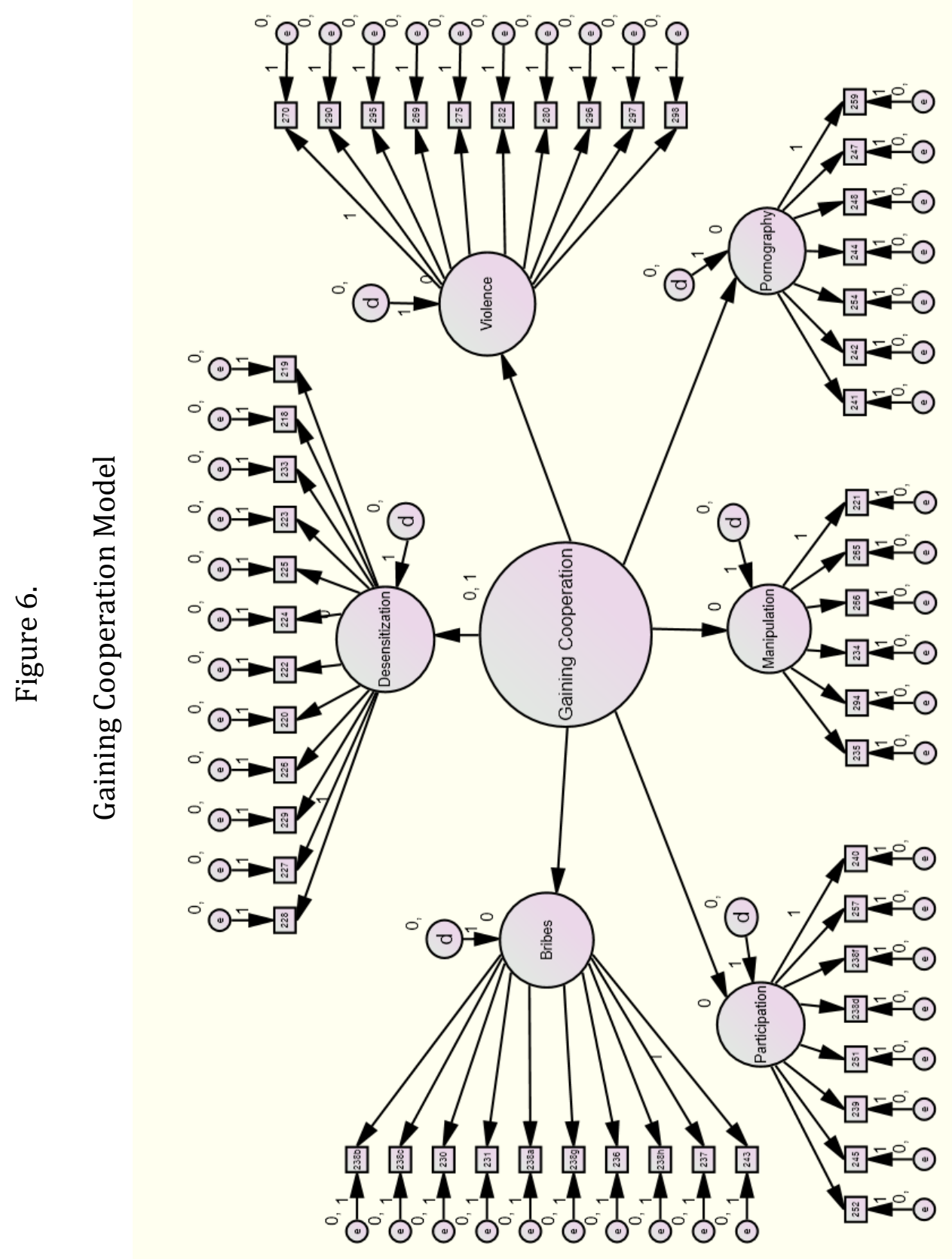


Figure 7

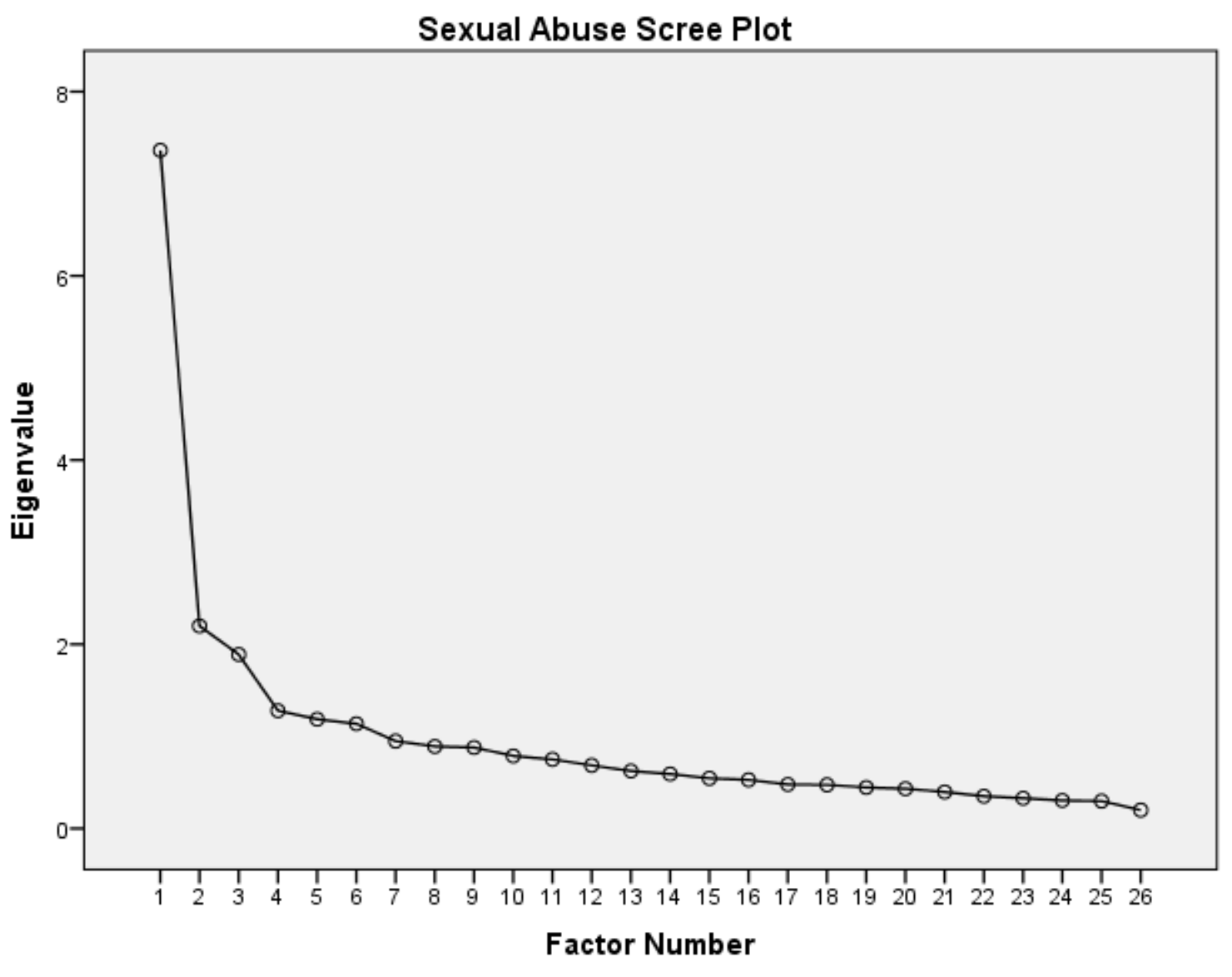




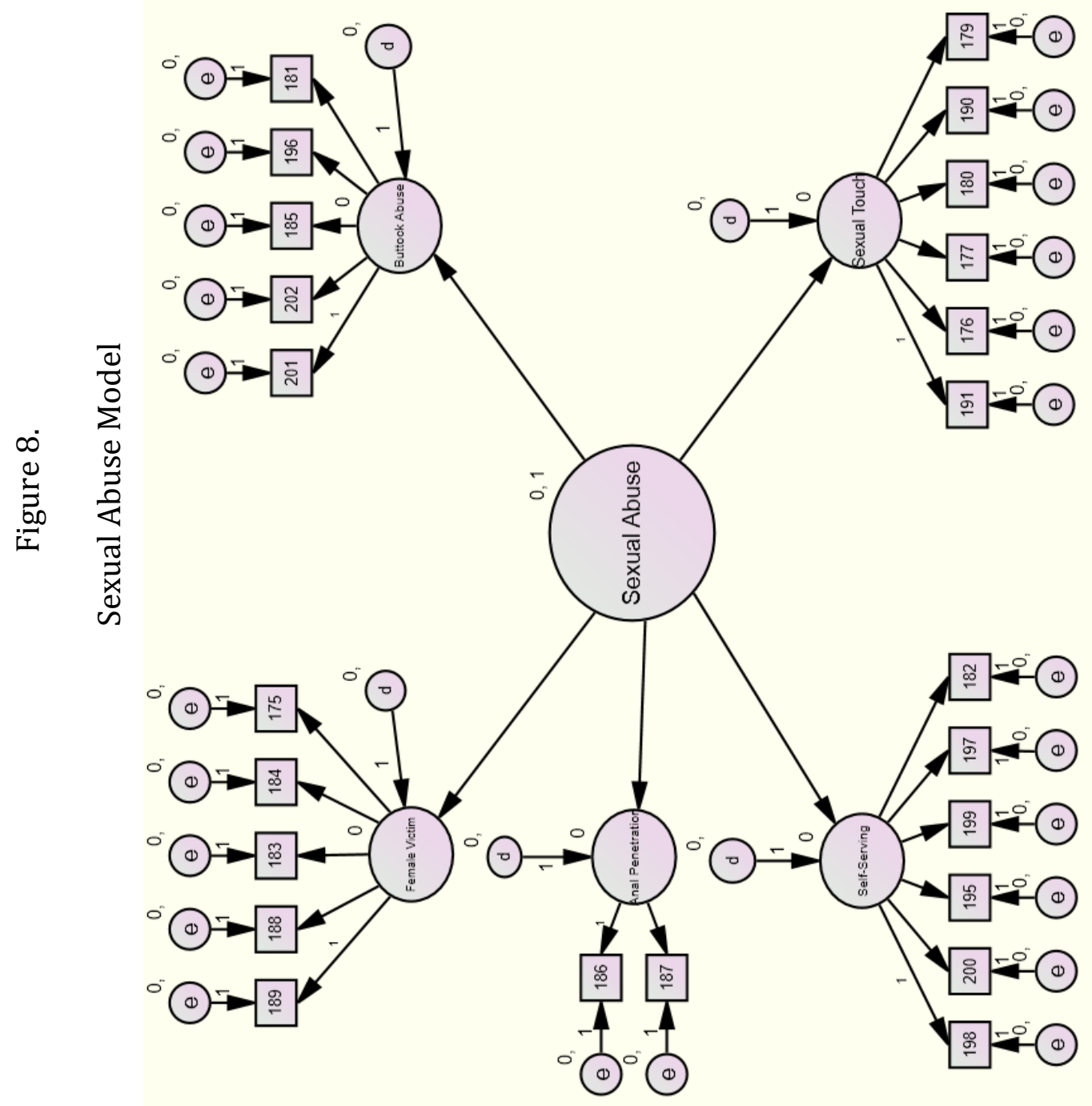


Figure 9.

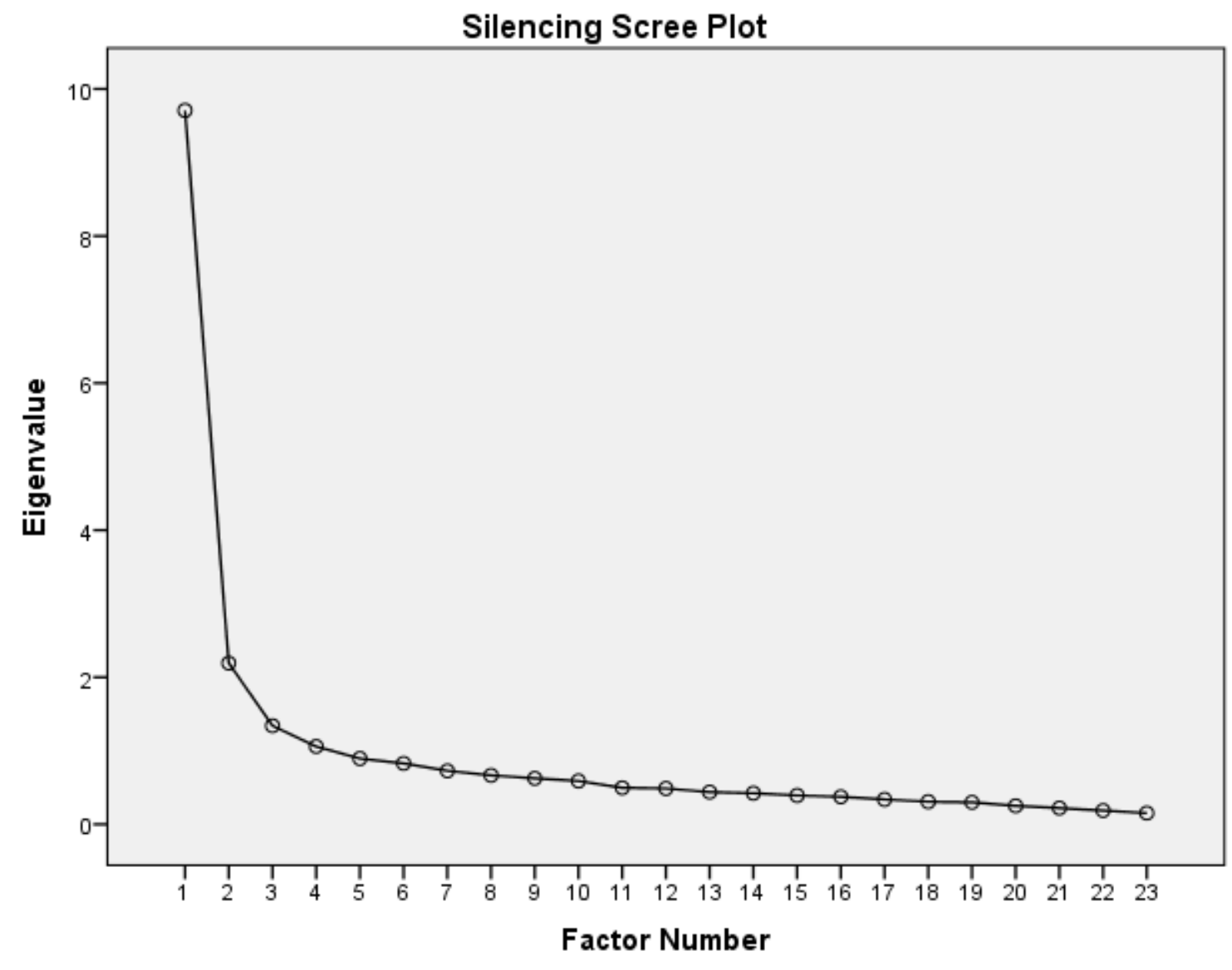




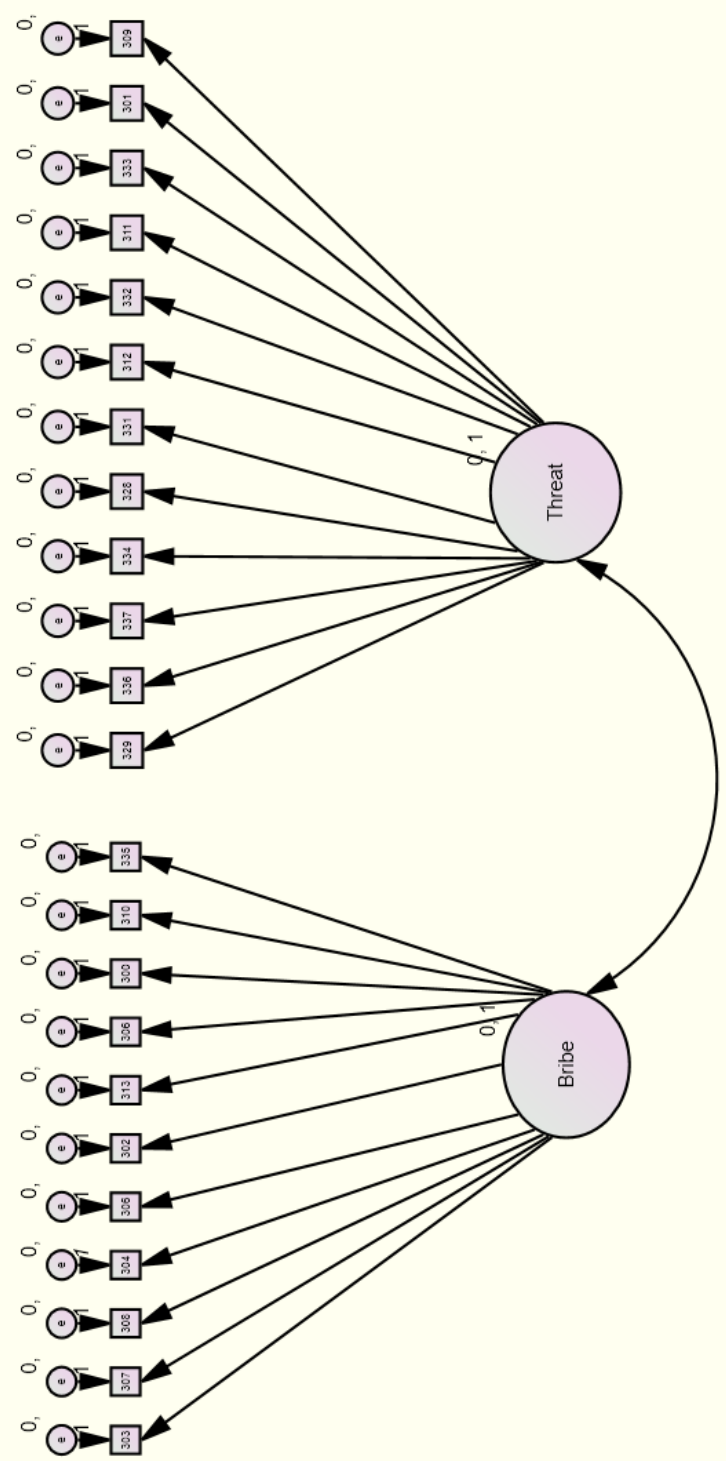




\section{References}

Akaike, H. (1974). A new look at the statistical model identification. IEEE transactions on automatic control, 19(6), 716-723.

Baker III, T. A., Connaughton, D. P., \& Zhang, J. J. (2010). An examination of immunity statutes regarding the liability of recreational youth sport organizations for the pedophilic actions of coaches, administrators, and officials. The ICHPER-SD Journal of Research in Health, Physical Education, Recreation, Sport \& Dance, 5(1), 54.

Beauregard, E., Rossmo, D. K., \& Proulx, J. (2007). A descriptive model of the hunting process of serial sex offenders: A rational choice perspective. Journal of Family Violence, 22(6), 449-463.

Bentler, P. M. (1990). Comparative fit indexes in structural models. Psychological bulletin, 107(2), 238.

Bentler, P. M., \& Bonett, D. G. (1980). Significance tests and goodness of fit in the analysis of covariance structures. Psychological bulletin, 88(3), 588.

Berliner, L., \& Conte, J. R. (1990). The process of victimization: The victims' perspective. Child abuse \& neglect, 14(1), 29-40.

Budin, L. E., \& Johnson, C. F. (1989). Sex abuse prevention programs: Offenders' attitudes about their efficacy. Child Abuse \& Neglect, 13(1), 77-87.

Butchart, A., Harvey, A. P., Mian, M., \& Furniss, T. (2006). Preventing child maltreatment: a guide to taking action and generating evidence. 
Carr, A., Dooley, B., Fitzpatrick, M., Flanagan, E., Flanagan-Howard, R., \& Tierney, K. (2010). Adult adjustment of survivors of institutional child abuse in Ireland. Child Abuse \& Neglect, 34(7), 477-489.

Centers for Disease Control and Prevention (2004). Sexual violence prevention: beginning the dialogue. Atlanta, GA: Centers for Disease Control and Prevention; 2004.

Centers for Disease Control and Prevention, National Center for Injury Prevention and Control (2007). Preventing Child Sexual Abuse Within Youth-serving Organizations: Getting Started on Policies and Procedures.

Colton, M., Roberts, S., \& Vanstone, M. (2012). Learning lessons from men who have sexually abused children. The Howard Journal of Criminal Justice, 51(1), 7993.

Conte, J. R., Wolf, S., \& Smith, T. (1989). What sexual offenders tell us about prevention strategies. Child abuse \& neglect, 13(2), 293-301.

Cornish, D. B. (1994). The procedural analysis of offending and its relevance for situational prevention. Crime prevention studies, 3, 151-196.

Cornish, D., \& Clarke, R. (1986). The reasoning criminal: Rational choice perspective on offending. New York: Springer.

Cornish, D. B., \& Clarke, R. V. (1987). Understanding crime displacement: An application of rational choice theory. Criminology, 25(4), 933-948.

Cornish, D. B., \& Clarke, R. V. (2002). Crime as a rational choice. Criminological 
Theories: Bridging the Past to the Future, 77-96.

Cornish, D. B., \& Clarke, R. V. (2003). Opportunities, precipitators and criminal decisions: A reply to Wortley's critique of situational crime prevention. Crime prevention studies, 16, 41-96.

Costello, Anna B. \& Jason Osborne (2005). Best practices in exploratory factor analysis: Four recommendations for getting the most from your analysis. Practical Assessment Research \& Evaluation, 10(7).

Cronbach, L. J. (1951). Coefficient alpha and the internal structure of tests. psychometrika, 16(3), 297-334.

Crosson-Tower, C. (2005). Extrafamilial sexual abuse, misuse and exploitation. Allyn \& Bacon/Longman.

Cuevas, C. A., Finkelhor, D., Clifford, C., Ormrod, R. K., \& Turner, H. A. (2010). Psychological distress as a risk factor for re-victimization in children. Child Abuse \& Neglect, 34(4), 235-243.

Cusson, M. (1993). Situational deterrence: Fear during the criminal event. Crime prevention studies, 1, 55-68.

Desai, S., Arias, I., Thompson, M. P., \& Basile, K. C. (2002). Childhood victimization and subsequent adult revictimization assessed in a nationally representative sample of women and men. Violence and victims, 17(6), 639-653.

De Souza, E., \& Miller, J. (2012). Homicide in the brazilian favela: Does opportunity make the killer?. British Journal of Criminology, 52(4), 786-807. 
Elliott, I. A., \& Beech, A. R. (2009). Understanding online child pornography use: Applying sexual offense theory to internet offenders. Aggression and Violent Behavior, 14(3), 180-193.

Fater, K., \& Mullaney, J. A. (2000). The lived experience of adult male survivors who allege childhood sexual abuse by clergy. Issues in Mental Health Nursing, 21(3), 281-295.

Firestone, P., Moulden, H. M., \& Wexler, A. F. (2009). Clerics who commit sexual offenses: Offender, offense, and victim characteristics. Journal of child sexual abuse, 18(4), 442-454.

Fischer, D. G., \& McDonald, W. L. (1998). Characteristics of intrafamilial and extrafamilial child sexual abuse. Child Abuse \& Neglect, 22(9), 915-929.

Gönültaş, B. M., \& Sahin, B. (2016). Event locations in extra-familial child sexual molestation cases the istanbul example. International Journal of Offender Therapy and Comparative Criminology, $0306624 X 16673373$.

Gorsuch, R. L. (1990). Common factor analysis versus component analysis: Some well and little known facts. Multivariate Behavioral Research, 25(1), 33-39.

Groff, E. R. (2007). Simulation for theory testing and experimentation: An example using routine activity theory and street robbery. Journal of Quantitative Criminology, 23(2), 75-103.

Harris, J. A. (1995). Confirmatory factor analysis of the aggression questionnaire. Behaviour Research and Therapy, 33(8), 991-993. 
Hu, L. T., \& Bentler, P. M. (1999). Cutoff criteria for fit indexes in covariance structure analysis: Conventional criteria versus new alternatives. Structural equation modeling: a multidisciplinary journal, 6(1), 1-55.

Isely, P.J., Isley, P., Freiburger, J. and McMackin, R. 2008. In their own voices: A qualitative study of men abused as children by catholic clergy. Journal of Child Sexual Abuse, 17(3-4): 201-215.

James, J., \& Proulx, J. (2016). The modus operandi of serial and nonserial sexual murderers: A systematic review. Aggression and Violent Behavior, 31, 200218.

Kaiser, H. F. (1959). Computer program for varimax rotation in factor analysis. Educational and psychological measurement, 19(3), 413-420.

Kaufman, K. L. (1989). Modus operandi questionnaire. Children's Hospital, Columbus, Ohio.

Kaufman, K. L. (1994). Modus Operandi Questionnaire (revised version). Columbus, OH: Children's Hospital.

Kaufman, K. L., Wallace, A. M., Johnson, C. F., \& Reeder, M. L. (1995). Comparing female and male perpetrators' modus operandi: Victims' reports of sexual abuse. Journal of Interpersonal Violence, 10(3), 322-333.

Kaufman, K., Hilliker, D., \& Daleiden, E. (November, 1995). Clinical applications of the Adolescent Modus Operandi Questionnaire. Fourteenth Annual Research \& Treatment Conference of The Association for the Treatment of Sexual Abusers. 
New Orleans, LA.

Kaufman, K., \& Daleiden, E. (July, 1995). Assessing adolescent sexual offenders' modus operandi: An approach to enhancing treatment planning. Texas Council on Sex Offender Treatment Annual Conference. Austin, TX.

Kaufman, K. \& Uncapher, S. (June, 1995). Enhancing treatment planning through the assessment of adolescent sex offenders' Modus Operandi. State-wide "Reclaim Ohio" Conference, Department of Youth Services. Columbus, OH.

Kaufman, K., Daleiden, E., Hilliker, D., \& Wallace, A. (June, 1995). Assessing adolescent sexual offenders' "Modus Operandi". Annual meeting of the American Professional Society on the Abuse of Children. Tucson, AZ.

Kaufman, K. L., Hilliker, D. R., \& Daleiden, E. L. (1996). Subgroup differences in the modus operandi of adolescent sexual offenders. Child Maltreatment, 1(1), 1724.

Kaufman, K.L., McCrady., F., Homlberg, J., Rotzien, A., Orts, K., \& Hilliker, E. (1997). Factor structure of the behaviors of offenders as measured by the modus operandi questionnaire. Poster session presented at the $16^{\text {th }}$ Annual Research and Treatment Conference of The Association for the Treatment of Sexual Abusers, Arlington, VA.

Kaufman, K. L., Holmberg, J. K., Orts, K. A., McCrady, F. E., Rotzien, A. L., Daleiden, E. L., \& Hilliker, D. R. (1998). Factors influencing sexual offenders' modus operandi: An examination of victim-offender relatedness and age. Child Maltreatment, 3(4), 349-361. 
Kaufman, K. L., Mosher, H., Carter, M., \& Estes, L. (2006). Empirically based situational prevention model for child sexual abuse (From Situational Prevention of Child Sexual Abuse, P 101-144, 2006, Richard Wortley and Stephen Smallbone, eds.--See NCJ-215297).

Kaufman, K., Hayes, A., \& Knox, L. A. (2010). The situational prevention model: Creating safer environments for children and adolescents.

Kline, R. B. (2011). Principles and practice of structural equation modeling. New York: Guilford Press Google Scholar.

Kloess, J. A., Seymour-Smith, S., Hamilton-Giachritsis, C. E., Long, M. L., Shipley, D., \& Beech, A. R. (2015). A Qualitative analysis of offenders' modus operandi in sexually exploitative interactions with children online. Sexual abuse: $a$ journal of research and treatment, 1079063215612442.

Lacoste, J., \& Tremblay, P. (2003). Crime and innovation: A script analysis of patterns in check forgery. Crime prevention studies, 16, 169-196.

Lang, R. A., \& Frenzel, R. R. (1988). How sex offenders lure children. Annals of Sex Research, 1(2), 303-317.

McGrath, R. J., Lasher, M. P., Cumming, G. F., Langton, C. M., \& Hoke, S. E. (2014). Development of vermont assessment of sex offender risk-2 (VASOR-2) Reoffense Risk Scale. Sexual Abuse, 26(3), 271-290.

Leclerc, B., \& Cale, J. (2015). Weapon use and sexual abuse outcomes: A multivariate 
and conjunctive analysis of sexual offenses against women. Security Journal, 28(1), 54-70.

Leclerc, B., Carpentier, J., \& Proulx, J. (2006). Strategies adopted by sexual offenders to involve children in sexual activity. In R. Wortley \& S. Smallbone (Eds.), Situational prevention of child sexual abuseCrime Prevention Studies, Vol. 19. (pp. 251-270). Monsey, N.Y.: Criminal Justice Press.

Leclerc, B., Proulx, J., \& Beauregard, E. (2009). Examining the modus operandi of sexual offenders against children and its practical implications. Aggression and violent behavior, 14(1), 5-12.

Leclerc, B., Proulx, J., \& McKibben, A. (2005). Modus operandi of sexual offenders working or doing voluntary work with children and adolescents. Journal of Sexual Aggression, 11(2), 187-195.

Leclerc, B., Smallbone, S., \& Wortley, R. (2015). Prevention nearby: The influence of the presence of a potential guardian on the severity of child sexual abuse. Sexual Abuse, 27(2), 189-204.

Leclerc, B., Wortley, R., \& Smallbone, S. (2010). An exploratory study of victim resistance in child sexual abuse: Offender modus operandi and victim characteristics. Sexual Abuse, 22(1), 25-41.

Leclerc, B., \& Felson, M. (2016). Routine activities preceding adolescent sexual abuse of younger children. Sexual Abuse, 28(2), 116-131.

Leclerc, B., \& Wortley, R. (2015). Predictors of victim disclosure in child sexual 
abuse: Additional evidence from a sample of incarcerated adult sex offenders. Child abuse \& neglect, 43, 104-111.

Mannon, J. 1997. Domestic and Intimate Violence: An application of routine activities theory. Aggression and Violent Behavior 2(1):9-24.

Marques, J. K., Wiederanders, M., Day, D. M., Nelson, C., \& Van Ommeren, A. (2005). Effects of a relapse prevention program on sexual recidivism: Final results from California's Sex Offender Treatment and Evaluation Project (SOTEP). Sexual Abuse: A Journal of Research and Treatment, 17(1), 79-107.

McDonald, R. P. (1978). Generalizability in factorable domains: “Domain validity and generalizability." Educational and Psychological Measurement, 38, 75-79.

Pereda, N., Guilera, G., Forns, M., \&amp; Gómez-Benito, J. (2009). The prevalence of child sexual abuse in community and student samples: A meta-analysis. Clinical psychology review, 29(4), 328-338.

Pratt, T.C. (2008). Rational choice theory, crime control policy, and criminological relevance. Criminology \& Public Policy, 7(1), 43-52

Rebocho, M. F., \& Gonçalves, R. A. (2012). Sexual predators and prey: A comparative study of the hunting behavior of rapists and child molesters. Journal of interpersonal violence, 27(14), 2770-2789.

Reynald, D. M., \& Elffers, H. (2009). The future of newman's defensible space theory linking defensible space and the routine activities of place. European Journal of Criminology, 6(1), 25-46. 
Schreck, C. J., \& Fisher, B. S. (2004). Specifying the influence of family and peers on violent victimization extending routine activities and lifestyles theories. Journal of interpersonal violence, 19(9), 1021-1041.

Shakeshaft, C. (2004). Educator sexual misconduct: A synthesis of existing literature. PPSS 2004-09. US Department of Education.

Smallbone, S., \& Wortley, R. K. (2000). Child sexual abuse in Queensland: Offender characteristics and modus operandi. Brisbane: Queensland Crime Commission and Queensland Police Service.

Steiger, J. H., \& Lind, J. C. (1980). Statistically based tests for the number of common factors. In annual meeting of the Psychometric Society, Iowa City, IA (Vol. 758, pp. 424-453).

Sullivan, J. Beech. AR, Craig, LE, \& Gannon, TA (2010). Comparing intra-familial and extra-familial child sexual abusers with professionals who have sexually abused children with whom they work. International Journal of Offender Therapy and Comparative Criminology.

Tabachnick, B. G., Fidell, L. S., \& Osterlind, S. J. (2001). Using multivariate statistics. Thorndike, R. M., Cunningham, G. K., Thorndike, R. L., \& Hagan, E. P. (1991). Measurement and evaluation in psychology and education (5th ed.). New York: Macmillan.

Tofte, S., \& Fellner, J. (2007). No Easy Answers: Sex Offender Laws in the US (Vol. 19, No. 4). Human Rights Watch.

Uliando, A., \& Mellor, D. (2012). Maltreatment of children in out-of-home care: A 
review of associated factors and outcomes. Children and youth services review, 34(12), 2280-2286.

Van Gijn, E. L., \& Lamb, M. E. (2013). Alleged sex abuse victims' accounts of their abusers' modus operandi. Journal of Forensic Social Work, 3(2), 133-149.

Van Prooijen, J. W., \& Van Der Kloot, W. A. (2001). Confirmatory analysis of exploratively obtained factor structures. Educational and Psychological Measurement, 61(5), 777-792.

Veneziano, C., Veneziano, L., \& LeGrand, S. (2000). The relationship between adolescent sex offender behaviors and victim characteristics with prior victimization. Journal of Interpersonal Violence, 15(4), 363-374.

Wijkman, M., Bijleveld, C., \& Hendriks, J. (2014). Juvenile female sex offenders: Offender and offence characteristics. European journal of criminology, 11(1), 23-38.

Wolfe, D. A., Francis, K. J., \& Straatman, A. L. (2006). Child abuse in religiouslyaffiliated institutions: Long-term impact on men's mental health. Child Abuse \& Neglect, 30(2), 205-212.

Wolfe, D. A., Jaffe, P. G., Jetté, J. L., \& Poisson, S. E. (2003). The impact of child abuse in community institutions and organizations: Advancing professional and scientific understanding. Clinical Psychology: Science and Practice, 10(2), 179191.

Wortley, R. (2001). A classification of techniques for controlling situational 
precipitators of crime. Security Journal, 14(4), 63-82.

Wyatt, G. E., \& Peters, S. D. (1986). Issues in the definition of child sexual abuse in prevalence research. Child abuse \& neglect, 10(2), 231-240.

Yar, M. (2005). The novelty of 'cybercrime': An assessment in light of routine activity theory. European Journal of Criminology, 2(4), 407-427.

Zinbarg, R. E., Revelle, W., Yovel, I., \& Li, W. (2005). Cronbach's $\alpha$, Revelle’s $\beta$, and McDonald's $\omega \mathrm{H}$ : Their relations with each other and two alternative conceptualizations of reliability. psychometrika, 70(1), 123-133. 